\title{
A Lagrangian view of convective sources for transport of air across the Tropical Tropopause Layer: distribution, times and the radiative influence of clouds
}

\author{
A. Tzella ${ }^{1, *}$ and B. Legras ${ }^{1}$ \\ ${ }^{1}$ Laboratoire de Météorologie Dynamique, CNRS, UMR8539, Ecole Normale Supérieure, 24 rue Lhomond, \\ Paris, 75005, France \\ *now at: School of Mathematics, University of Edinburgh, Edinburgh EH93JZ, UK
}

Received: 14 June 2011 - Published in Atmos. Chem. Phys. Discuss.: 28 June 2011

Revised: 1 November 2011 - Accepted: 4 December 2011 - Published: 13 December 2011

\begin{abstract}
The tropical tropopause layer (TTL) is a key region controlling transport between the troposphere and the stratosphere. The efficiency of transport across the TTL depends on the continuous interaction between the large-scale advection and the small-scale intermittent convection that reaches the Level of Zero radiative Heating (LZH). The wide range of scales involved presents a significant challenge to determine the sources of convection and quantify transport across the TTL. Here, we use a simple Lagrangian model, termed TTL detrainment model, that combines a large ensemble of 200-day back trajectory calculations with highresolution fields of brightness temperatures (provided by the CLAUS dataset) in order to determine the ensemble of trajectories that are detrained from convective sources. The trajectories are calculated using the ECMWF ERA-Interim winds and radiative heating rates, and in order to establish the radiative influence of clouds, the latter rates are derived both under all-sky and clear-sky conditions.

We show that most trajectories are detrained near the mean LZH with the horizontal distributions of convective sources being highly-localized, even within the space defined by deep convection. As well as modifying the degree of source localization, the radiative heating from clouds facilitates the rapid upwelling of air across the TTL. However, large-scale motion near the fluctuating LZH can lead a significant proportion of trajectories to alternating clear-sky and cloudy regions, thus generating a large dispersion in the vertical transport times. The distributions of vertical transport times are wide and skewed and are largely insensitive to a bias of about
\end{abstract}

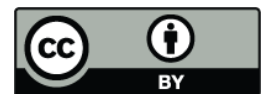

Correspondence to: A. Tzella (a.tzella@ed.ac.uk) $\pm 1 \mathrm{~km}(\mp 5 \mathrm{~K})$ in the altitude of cloud top heights (the main sensitivity appearing in the times to escape the immediate neighbourhood of the LZH) while some seasonal and regional transport characteristics are apparent for times up to 60 days. The strong horizontal mixing that characterizes the TTL ensures that most air of convective origin is well-mixed within the tropical and eventually within the extra-tropical lower-stratosphere.

\section{Introduction}

It is now widely accepted that most of the transport of tropospheric air into the stratospheric "overworld" at potential temperatures above about $380 \mathrm{~K}$ takes place in the tropics (see reviews by Holton et al., 1995; Stohl et al., 2003), across what is now known as the Tropical Tropopause Layer (TTL) (Highwood and Hoskins, 1998; Folkins et al., 1999; Fueglistaler et al., 2009a). This layer, whose vertical extent is over several kilometres, spans the gradual transition from a region dominated by the convectively overturning motion of the Hadley-Walker circulation to a region of slow ascent, controlled by the tropical branch of the Brewer-Dobson circulation. The efficiency at which air is transported across the TTL depends on both the large-scale advection and the local sources of deep convection. A detailed quantification of their combined effect is challenging because of the large range of scales involved. Such a quantification is particularly important for halogenated Very Short-Lived Substances (VSLS) whose impact on ozone depletion relies on their efficient transport into the stratosphere (see e.g. WMO, 2007).

Published by Copernicus Publications on behalf of the European Geosciences Union. 
Air from the boundary layer is rapidly (within hours) transported into the TTL by deep convection. The latter frequently penetrates the region near the TTL base, commonly taken to lie above the level of maximum convective outflow (between 345-355 K, 12-14 km; see e.g. Gettelman and de Forster, 2002; Fueglistaler et al., 2009a). However, most air detrained in this region descends back to the boundary layer. With increasing altitude, convection becomes increasingly rare (see e.g. Liu and Zipser, 2005; Fu et al., 2007) while the decrease of temperature leads to a significant drop in water vapour. As a result, the magnitude of the radiative cooling outside the clouds decreases with altitude, leading to a smaller descending mass-flux. This decrease continues up until a certain level, situated at about $360 \mathrm{~K}(15 \mathrm{~km})$, that marks the transition from clear-sky radiative cooling to radiative heating (Gettelman et al., 2004). Once above this level, known as the Clear sky Level of Zero radiative Heating (CLZH), the majority of air originating from deep convection is transported into the stratosphere.

The mean 5-15 K $(1-3 \mathrm{~km})$ gap between the level of maximum convective outflow and the mean C-LZH implies that the number of convective sources that can penetrate the CLZH is potentially too small to explain the large-scale upward mass-flux in the Brewer-Dobson circulation. This discrepancy is accounted for by considering the radiative influence of opaque clouds near their top as well as cirrus clouds (Yang et al., 2010). The latter are omnipresent in the TTL (e.g., Wang et al., 1996; Martins et al., 2011), generated either from the outflow of deep convective anvils or in situ condensation (e.g., Massie et al., 2002), with lifetimes of a few days, reaching horizontal scales of the order of $1000 \mathrm{~km}$ (e.g., Winker and Trepte, 1998). Using a large number of detailed radiative transfer calculations to quantify upwelling and subsidence in cloudy and cloud-free air, Corti et al. (2005) showed that the All-sky Level of Zero radiative Heating (A-LZH) is on average about $\sim 355 \mathrm{~K}(14 \mathrm{~km})$, i.e., $\sim 5 \mathrm{~K}(1 \mathrm{~km})$ lower than the C-LZH. The gap between the A-LZH and the mean level of maximum convective outflow is thus reduced, facilitating a larger proportion of air to be transported into the stratosphere. The net radiative heating associated with solar absorption by cloud tops and infrared heating by cirrus clouds (which within cirrus clouds is $\sim 1 \mathrm{~K} \mathrm{day}^{-1}$ ) allows for the rapid transport of air upwards, up to the C-LZH, above which their radiative influence becomes increasingly small. According to Corti et al. (2006), it can take as little as two weeks (a time sufficiently short for most VSLS) for air of convective origin to reach the $370 \mathrm{~K}$ surface, if the air remains inside cirrus clouds for most of the time.

The above descriptions and estimates are based on mean vertical profiles and thus do not take into account the detailed pathways of cloud air (i.e., air originating from deep convection). These pathways are largely controlled by largescale horizontal advection that, in this region of the atmosphere, can transport cloud air along great longitudinal distances (Holton and Gettelman, 2001; Fueglistaler et al., 2004; Bonazzola and Haynes, 2004). Horizontal transport could play a significant role in the vertical transport of cloud air into the stratosphere. Because clouds are spatially localized and intermittent, both the heating rates and the ALZH are highly fluctuating in space and time. In contrast, in clear-sky, the distributions of heating rates are, in general, smoother. Horizontal motion can thus transport cloud air that is detrained within a certain region into other regions, with very different vertical heating rate profiles. As a result, cloud air detrained above the A-LZH may subside back into the troposphere or remain for a long time near the A-LZH so that its motion is fluctuating in the vertical direction. The combined effect of the radiative heating associated with clouds and the large-scale horizontal flow for transport of air of convective origin into the stratosphere is a priori unknown.

To examine this effect, in this paper we use a simple Lagrangian model, termed TTL detrainment model, that combines a large number of back trajectory calculations with high-resolution global fields of brightness temperatures. Our particular focus is to determine the ensemble of trajectories that are detrained from deep convection. This ensemble is then used to deduce the distribution of convective sources and times for transport of cloud air across the TTL. The trajectories are calculated using the European Centre of Medium-range Weather Forecast (ECMWF) ERA-Interim re-analysis winds and radiative heating rates, derived both under all-sky and clear-sky conditions so that the radiative influence of clouds is established. The brightness temperature data are obtained from the CLoud Archive User Service (CLAUS). In order to evaluate the sensitivity of the results to biases in the brightness temperature we consider a variable offset of $\Delta T= \pm 5 \mathrm{~K}$.

In the next section we present the model, data and trajectory calculations used in this study. In Sect. 3 we present our results. We last conclude in Sect. 4.

\section{Data and method: the TTL detrainment model}

\subsection{Trajectory calculations}

We employ large-scale wind and temperature fields to calculate an ensemble of back trajectories whose initial positions are uniformly distributed on two iso-pressure surfaces that lie in the upper TTL and lower stratosphere: $100 \mathrm{hPa}$ and $70 \mathrm{hPa}$. The trajectories are initialised on a high-resolution $1^{\circ} \times 1^{\circ}$ longitude/latitude grid between $50^{\circ} \mathrm{N}$ and $50^{\circ} \mathrm{S}$, at all longitudes (36,360 trajectories). This range of latitudes encompasses the latitude range of the TTL in all seasons. On these surfaces, the potential temperatures vary between low values at the equator that depend on the season - the mean January (July) potential temperature is $380 \mathrm{~K}(385 \mathrm{~K})$ for the $100 \mathrm{hPa}$ surface and $430 \mathrm{~K}(415 \mathrm{~K})$ for the $70 \mathrm{hPa}$ surface and large values at the poleward boundaries that are weakly 


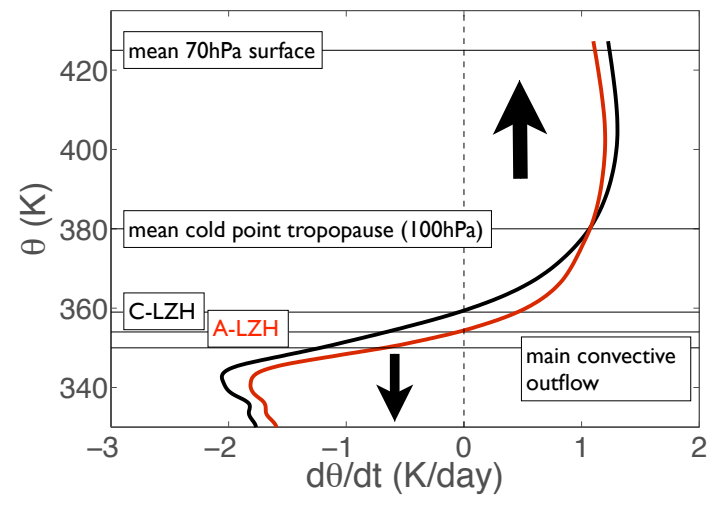

(a)

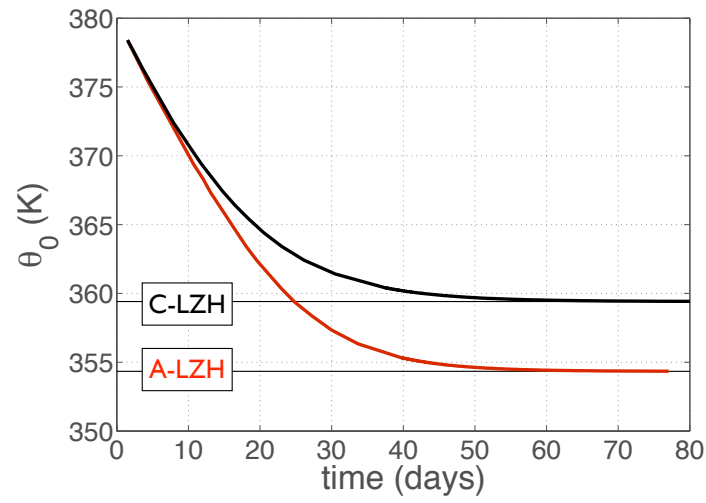

(b)

Fig. 1. (a) Annual mean tropical radiative heating rates $\left(30^{\circ} \mathrm{S}-30^{\circ} \mathrm{N}\right)$ represented as change in potential temperatures, calculated for all-sky (in red) and clear-sky (in black) conditions, using the ERA-Interim dataset for 2005. (b) Time for transport from a source level, $\theta_{0}$, to $380 \mathrm{~K}$, calculated using the profiles shown in (a).

affected by the season - the mean potential temperature is $420 \mathrm{~K}$ on the $100 \mathrm{hPa}$ surface and $465 \mathrm{~K}$ on the $70 \mathrm{hPa}$ surface.

We use these back trajectories to investigate the characteristics of convective sources for transport of cloud air across the TTL, eventually reaching a destination in the tropics or the extratropics at 100 or $70 \mathrm{hPa}$. A main motivation lies in understanding how these sources influence the distributions of VSLS in the upper TTL and the lower stratosphere. The lifetimes of VSLS are by definition less than 6 months (see e.g. WMO, 2007). Therefore, 200-day simulations are both sufficient and necessary for our purposes. Note that 200 days is sufficiently long to sample the rapid exchanges between the tropical and extra-tropical lower stratosphere, occurring at timescales faster than those associated with the deep branch of the Brewer-Dobson circulation. Our focus is on determining the convective sources for 2005. In order that all sources in 2005 are equally sampled, we set the launch period to cover a period between the 1st of January 2005 and the 30 June 2006. The trajectories are initialised at 12:00 UTC every 4 days resulting in a total of 5017680 $(138 \times 36360)$ trajectories.

The back trajectories are computed in an isentropic coordinate system (diabatic trajectories) with TRACZILLA, a modified version of FLEXPART (Stohl et al., 2005; Pisso and Legras, 2008), using analysis (at 00:00, 06:00, 12:00 and 18:00 UTC), 3-h forecasts (at 03:00, 09:00, 15:00, and 21:00 UTC) and 9-h forecasts (at 09:00 and 21:00 UTC) from the European Centre of Medium-range Weather Forecast (ECMWF) ERA-Interim re-analysis dataset (T255 spectral resolution, 60-level hybrid vertical coordinates and 12-h 4D-Var assimilation; see Dee et al., 2011). Diabatic trajectories have been found to be less dispersive than trajectories obtained by kinematic models in which transport is derived from three-dimensional wind fields (Schoeberl et al.,
2003; Stohl et al., 2004; Wohltmann and Rex, 2008). Although this difference is less prominent in the ERA-Interim dataset (Monge-Sanz et al., 2007; Liu et al., 2010), it may still be significant in reconstructing ozone profiles in the TTL (Konopka et al., 2009; Ploeger et al., 2011).

The horizontal (isentropic) part of the motion is obtained from the meteorological wind fields. First extracted on a $1^{\circ} \times 1^{\circ}$ longitude/latitude grid, the wind fields are linearly interpolated in the latitude, longitude and log-pressure along the trajectories. Trajectories are then integrated in time with a 15 min time-step. The vertical (cross-isentropic) part of the motion is derived from radiative heating rates, $Q_{\mathrm{rad}}$, provided as 3-h averages from forecasts of temperature tendencies. The vertical displacement is then given by

$$
\frac{d \theta}{d t}=\frac{\theta}{c_{p} T} Q_{\mathrm{rad}}
$$

where $\theta$ denotes potential temperature, $T$ temperature and $c_{p}$ the specific heat capacity per unit mass at constant pressure. In general, this part of the motion is derived from diabatic heating rates whose values can also depend on additional processes to radiative heating. However, as long as a trajectory remains in cloud-free air, the component of heating that is associated with the release of latent heat can be discarded while the contribution of heat transfer by turbulent motion and diffusion was previously found to be small (Fueglistaler et al., 2009b).

The radiative heating rates can be calculated in both clearsky and all-sky conditions in which case the radiative effect of different kinds of clouds is included. Calculating the contribution of clouds on the radiative heating rates can become quite involved, particularly in regions where both optically thick anvil clouds and thin cirrus clouds co-exist. The uncertainties in the radiative heating rates are thus larger in the lower TTL (see Fig. 7 in Fueglistaler et al., 2009b). The contribution of clouds to the radiative heating rates is, within the 

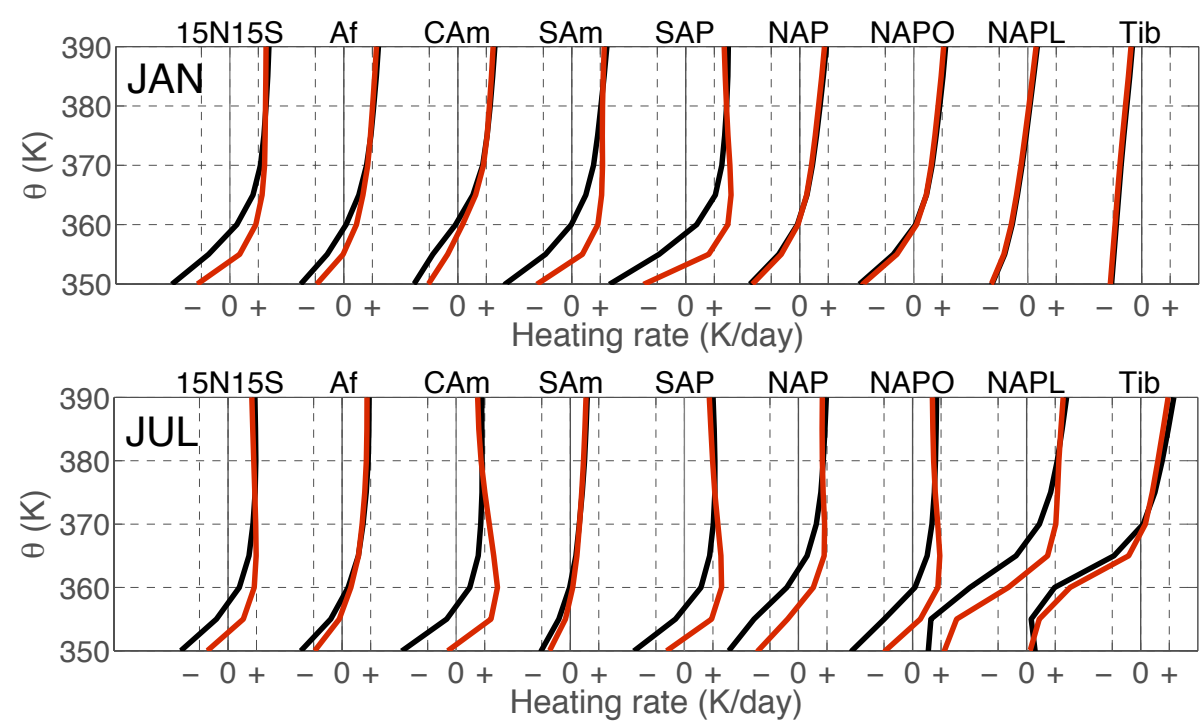

Fig. 2. Monthly mean radiative heating rates, represented as change in potential temperatures, calculated for January and July and both all-sky (in red) and clear-sky (in black) conditions, using the ERA-Interim dataset for 2005. The vertical profiles are obtained over the $15^{\circ} \mathrm{S}-15^{\circ} \mathrm{N}$ latitude band as well as 8 other geographical regions. Africa (Af): $\left(15^{\circ} \mathrm{S}-20^{\circ} \mathrm{N}\right) \times\left(40^{\circ} \mathrm{W}-20^{\circ} \mathrm{E}\right)$; C. America $(\mathrm{CAm})$ : $\left(0^{\circ}-\right.$ $\left.20^{\circ} \mathrm{N}\right) \times\left(110^{\circ} \mathrm{W}-60^{\circ} \mathrm{W}\right)$; S. America $(\mathrm{SAm})$ : $\left(35^{\circ} \mathrm{S}-0^{\circ}\right) \times\left(75^{\circ} \mathrm{W}-45^{\circ} \mathrm{W}\right)$; S. Asian-Pacific $(\mathrm{SAP}):\left(20^{\circ} \mathrm{S}-10^{\circ} \mathrm{N}\right) \times\left(70^{\circ} \mathrm{E}-120^{\circ} \mathrm{W}\right) ; \mathrm{N}^{\circ}$ Asian-Pacific (NAP): $\left(10^{\circ} \mathrm{N}-35^{\circ} \mathrm{N}\right) \times\left(70^{\circ} \mathrm{E}-120^{\circ} \mathrm{W}\right)$; N. Asian-Pacific Land (NAPL): $\left(20^{\circ} \mathrm{N}-35^{\circ} \mathrm{N}\right) \times\left(70^{\circ} \mathrm{E}-120^{\circ} \mathrm{E}\right)$; N. Asian-Pacific Ocean (NAPO): NAP-NAPL; Tibetan plateau (Tib): $\left(30^{\circ} \mathrm{N}-35^{\circ} \mathrm{N}\right) \times\left(80^{\circ} \mathrm{E}-95^{\circ} \mathrm{E}\right)$. The "+" and "_" signs on the horizontal axis respectively stand for +1 and $-1 \mathrm{Kday}^{-1}$. The shift between two successive profiles is $4 \mathrm{~K}_{\text {day }}{ }^{-1}$.

ECMWF model, obtained using statistical assumptions about the cloud distribution within the mesh. This calculation can thus not distinguish between the heating occurring inside the clouds from that occurring outside the clouds. We assume that as long as the trajectories are situated at the top or above deep convective clouds, the cloud component of the radiative heating is related to the effect of clouds on their environment.

We emphasize the use of radiative (instead of total diabatic) heating rates for the vertical part of the cloud-free motion. This is because the rapid, upward convective motion between the boundary layer and detrainment occurs over sub-grid horizontal scales of a few kilometres. This motion is parameterized within the ECMWF model and averaged within the mesh. The resolved vertical velocity or, equivalently, the total diabatic heating rate (including the release of latent heat), is, within the regions of convection, positive between the boundary layer and the tropopause. Thus, the descending air parcel motions associated with cloud-free regions between deep convective clouds are not represented. This lack of representation may lead to erroneous transport in the convective regions of the tropical troposphere.

As noted in the introduction, clouds can enhance the net tropical radiative heating rates (see e.g. Yang et al., 2010). This enhancement is reflected in the annual mean vertical tropical profiles of the radiative heating rates, shown in Fig. 1a, obtained for clear-sky and all-sky conditions from the ERA-Interim dataset for 2005. The differences between the two profiles result in different estimates for the time for transport between a source level in potential temperature, $\theta_{0}$, and the $380 \mathrm{~K}$ level (see Fig. 1b). These differences are especially important below $365 \mathrm{~K}$ where the estimated transport time is strongly dependent on the value of $\theta_{0}$, diverging as $\theta_{0}$ approaches the mean LZH (in either clear- or all-sky conditions) that acts as a barrier for transport between the mid and upper troposphere.

The above estimates do not take into account the horizontal part of the motion. They nevertheless point to the key role that cloud radiation has on transport across the TTL. In order to obtain a comprehensive quantification of the radiative influence of clouds on transport across the TTL, we here consider both all-sky and clear-sky radiative heating rates for the vertical part of the motion. Such a quantification has to some extent been examined in Ploeger et al. (2010) where it is found that vertical transport is indeed faster when the radiative influence of clouds is taken into account. Ploeger et al. (2010), however, focus on back trajectories arriving on fixed levels of $\theta_{0}$ that are not related to the potential temperature at which air of convective origin detrains.

Figure 2 shows the monthly mean vertical profiles of the radiative heating rates calculated from the EI dataset, for January and July 2005, over different regions and both clear-sky and all-sky conditions. It is clear that over the $15^{\circ} \mathrm{S}-15^{\circ} \mathrm{N}$ latitude band, the monthly profile differences are weak. There are, however, significant differences over a number of regions. These differences are associated with the cycle of convection. In particular, during active periods of 
convection, both the C-LZH and the A-LZH are lower, with the latter exhibiting a larger shift downwards. This is not so much the case for the southern Asian-Pacific region (SAP) because convection is active during both boreal winter and summer. It is clearly the case for central America (CAm) in which convection is not prevalent during boreal winter but is present during boreal summer and the regions of southern America (SAm) and Africa (Af) in which convection rarely takes place during boreal summer but is active during boreal winter. In the northern Asian-Pacific region (NAP), convection is only active during the period of monsoon. In this case, both the A-LZH and the C-LZH are higher by about $5 \mathrm{~K}$ with respect to their SAP counterparts. The NAP values are the combined contribution from the oceanic part of the NAP (which exhibits a lower C-LZH and A-LZH) and the continental part of the NAP (which exhibits an A-LZH of $362 \mathrm{~K}$ which is well above its standard value). Extreme values of $370 \mathrm{~K}$ are reached above the Tibetan plateau (Tib) for both the A-LZH and the C-LZH. This pattern is associated with the sloping up of the LZH in the subtropics (see Fig. 2 of Fueglistaler et al., 2009a). This suggests that, during boreal summer, part of the convective sources for transport of cloud air across the TTL should be located at potential temperatures that are higher than those obtained during boreal winter.

\subsection{Detrainment}

Our main aim is to determine and characterise the subensemble of trajectories that have encountered Convective Sources (CS), thereafter called the CS-TTL ensemble. To that end, we employ high-resolution fields of cloud top heights, estimated using satellite brightness temperature (BT) measurements based on the infra-red window (mean $10.8 \mu \mathrm{m}$ channel), obtained from CLAUS at $1 / 3^{\circ} \times$ $1 / 3^{\circ}$ spatial resolution and 3 -h temporal resolution (Hodges et al., 2000) that are mapped along the trajectories using piecewise constant interpolation. The use of BT to measure cloud top heights is based on the standard assumption that the temperature at the top of the cloud is equal to that of the environment at this location.

Note that CLAUS maps all types of clouds. However, here, we are only interested by the anvils produced by deep convection. This distinction cannot be made in the absence of available cloud classification at a global scale or information from other channels. The presence of high-altitude, semitransparent cirrus situated above the anvil may therefore introduce a possible bias in the cloud top heights. Other biases are related to the non-equilibrium evolution of the cloud that leads to temperature differences and cloud heterogeneity within the pixel (Sherwood et al., 2004). In order to take into account these sort of biases, we consider a variable offset, $\Delta T$, to the brightness temperatures that ranges within the $\pm 5 \mathrm{~K}$ interval (see Sect. 2.3 for more details on the CS-TTL ensembles that we obtain).
A trajectory is identified as a member of the CS-TTL ensemble if the time history of its temperature over the duration of the back-trajectory has at some point been larger than the temperature on the top of the cloud. In this case, the last encounter with a cloud is given by the first time (in backward time) at which the parcel's temperature becomes larger than the cloud top temperature. The remaining part of the back trajectory is thereafter ignored.

For the above rule to be well-posed, the cloud top height needs to be unambiguously defined in terms of temperature. This is indeed the case within the tropics where the temperature decreases monotonically with height until a distinct minimum is reached at approximately $380 \mathrm{~K}$ or $100 \mathrm{hPa}$. We therefore impose two further rules. The first rule is that the parcel's potential temperature at the encounter point is less than $380 \mathrm{~K}$ i.e., the position of the air parcel at this point lies below the tropical tropopause. The second rule is that the parcel's latitudinal position at the encounter point is constrained within $\left(30^{\circ} \mathrm{S}-30^{\circ} \mathrm{N}\right)$ except for the boreal summer season during which it is constrained within $\left(30^{\circ} \mathrm{S}-35^{\circ} \mathrm{N}\right)$. In practice, the precise value of this boundary is not important: because of subsidence in the subtropics, less than 5\% of the trajectories actually encounter a cloud at higher latitudes. The northward extension of the northern boundary during boreal summer is a mere consequence of the Asian Monsoon that drives continental convection towards higher latitudes.

The primary consequence of our algorithm is to eliminate the encounters of trajectories with clouds in the stratosphere. For it is now recognised that convective events that penetrate the tropopause are rare, representing less than $0.5 \%$ of the total number of convective events (Liu and Zipser, 2005; Fu et al., 2007) and are therefore unlikely to affect the total transport of mass across the tropopause. A quantity that could be more sensitive to overshooting events is the distribution of water vapour. However, it is now established that in the lower stratosphere, its distribution can be successfully reconstructed using large-scale wind and temperature fields, both globally (see e.g. Fueglistaler et al., 2005; James et al., 2008; Liu et al., 2010) and locally (Schiller et al., 2009). This suggests that most of its variability is controlled by slow dehydration induced by the large-scale motion.

The here described model, that we refer to as the TTL detrainment model, was previously introduced, within a different context, by Nawrath (2002) and James et al. (2008) to reconstruct distributions of water vapour in both the troposphere and the stratosphere. In this paper, we use this model as a way to identify the global distribution of convective sources and times for transport of cloud air across the TTL. This distribution is closely related to the distribution of sources in the boundary layer. At the same time, the distribution of times for transport of air into the upper TTL is expected to be similar for air originating from the boundary layer and air originating from the sources of convection. This is because the parcels' motion between the boundary layer 
and the point of detrainment is characterised by a rapid, vertical upward transfer that lasts a few tens of minutes (or at most several hours in the case of a thick anvil). Making the general assumption that the parcels that reach heights near the cloud top are those parcels that are less diluted by entrainment of environmental air, we deduce that, at the point of detrainment, the CS-TTL parcels' composition in non-soluble tracers is similar to the composition of the boundary layer at the same horizontal location.

We note that a modified version of the TTL detrainment model has recently been employed by Wright et al. (2011) to examine the relative contribution to stratospheric water vapour of different regions within South-East Asia during boreal summer. The main modification appears in the vertical motion of the trajectories: instead of radiative heating rates, Wright et al. (2011) employed total diabatic heating rates. For reasons discussed in Sect. 2.1, we have chosen radiative heating rates in order to better represent the motion outside clouds. For the sake of completeness, results obtained using total diabatic heating rates are briefly discussed at the end of Sects. 3.1 and 3.2.

\subsection{CS-TTL trajectory ensembles and their characteristics}

For each initial level, we perform two sets of simulations. The first one is performed using all-sky (ALLSKY) radiative heating rates and the second one using clear-sky (CLRSKY) radiative heating rates. For the all-sky simulations, we consider a variable offset to the brightness temperature of $\Delta T=$ $\pm 5 \mathrm{~K}$ that takes into account the presence of biases in the brightness temperatures (see also Sect. 2.2). It also tests the sensitivity of the results to such biases. No offset is considered for the clear-sky calculation. We thus obtain a set of four CS-TTL ensembles that we label as ALLSKY- $\Delta T 0$, ALLSKY- $\Delta$ T5, ALLSKY- $\Delta$ T-5 and CLRSKY- $\Delta T 0$.

Figure 3 shows that, when the trajectories are initialised at $100 \mathrm{hPa}$, the CS-TTL trajectories represent $80 \%$ of the entire set of trajectories for all-sky conditions and $72 \%$ for clearsky conditions. Half of the CS-TTL parcels have encountered a convective source within the last 40 (for $\Delta T=-5 \mathrm{~K}$ ) and 51 days (for $\Delta T=5 \mathrm{~K}$ ) for all-sky conditions. For clearsky conditions, the corresponding time is 75 days. The proportion of CS-TTL trajectories that have previously encountered a convective source between 90 and 200 days ago is non-negligible for all-sky conditions (17-30\%) and even more so for clear-sky conditions ( $39 \%$ for CLRSKY- $\Delta T 0$ ). When the parcels are initialised at $70 \mathrm{hPa}$, the CS-TTL trajectories represent a smaller proportion of the entire set of trajectories. This is due to the larger distance between the convective sources and the initial level as well as the larger proportion of back trajectories that end up in the extra-tropical stratosphere.

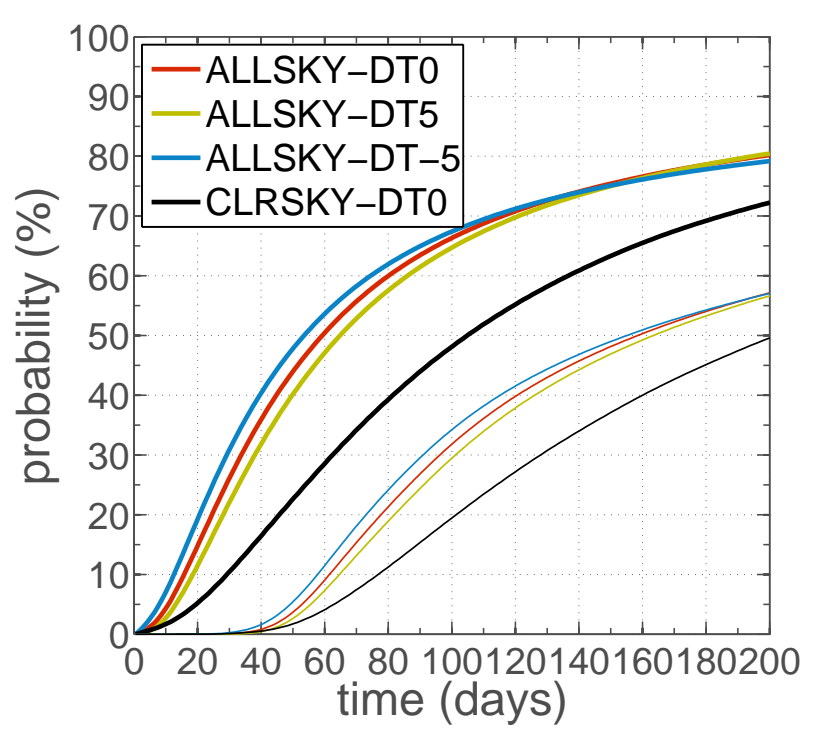

Fig. 3. Cumulative proportion of CS-TTL trajectories plotted as a function of time for transport of air between convective sources and the $100 \mathrm{hPa}$ (thick lines) and $70 \mathrm{hPa}$ (thin lines) surfaces. Results obtained from back trajectories, calculated in both clear-sky and all-sky conditions where different thermal biases were taken into account (see text for more details). The trajectories were launched between the beginning of 2005 and the middle of 2006, with cloud encounters restricted to 2005 .

\subsection{Remaining "free" trajectories}

The remaining parcels have never encountered a cloud at the end of their 200-day back-trajectory. The majority of these "free" parcels were, at the beginning of their back-trajectory, located within the extra-tropics (about $80 \%$ and $65 \%$ for launches at $100 \mathrm{hPa}$ and $70 \mathrm{hPa}$, respectively). Under allsky conditions, the majority of "free" parcels are, at the end of their back-trajectory, located at higher parts of the stratosphere $(\theta>400 \mathrm{~K})$, mostly within the extra-tropics, entrained within the (reverse) Brewer-Dobson circulation (about $70 \%$ and $75 \%$ ). Conversely, under clear-sky conditions, the corresponding proportions are smaller (about $40 \%$ and $55 \%$ ).

The difference between all-sky and clear-sky conditions is particularly significant when looking at the proportion of "free" parcels that, at the end of their back trajectory, are concentrated below the $360 \mathrm{~K}$ surface. For trajectories initially launched at $100 \mathrm{hPa}$, the corresponding proportions are notably smaller for all-sky conditions (6-11\%) than for clearsky conditions $(26 \%)$. This large difference between allsky and clear-sky conditions implies that the region near the mean tropical C-LZH is a sort of "stagnation" region. As we shall see in Sect. 3.2, air parcels that are detrained within this region can take a long time to exit from it. Equivalently, it takes a long time for back trajectories to encounter a source of convection within this region. For these "free" trajectories, the necessary time exceeds 200 days. 
Table 1. Seasonal mean characteristics of convective sources and times for transport of air between detrainment and launch. Calculations made using the ALLSKY- $\Delta T 0$ trajectory ensemble, launched at $100 \mathrm{hPa}$. The values for the median, $\mu_{1 / 2}$, and standard deviation, $\sigma$, are given in parenthesis.

\begin{tabular}{lcccc}
\hline & DJF & MAM & JJA & SON \\
\hline CS-TTL parcels, $\%$ & 27 & 27 & 22 & 23 \\
Cloud Temperature, K $\left(\mu_{1 / 2}, \sigma\right)$ & $205(205,9)$ & $205(205,9)$ & $205(205,9)$ & $205(205,9)$ \\
Parcel potential temperature, K $\left(\mu_{1 / 2}, \sigma\right)$ & $354(353,3.72)$ & $354(353,3.6)$ & $357(356,6.2)$ & $353(352,5.3)$ \\
Transit-time, days $\left(\mu_{1 / 2}, \sigma\right)$ & $59(44,47)$ & $61(46,47)$ & $62(51,43)$ & $55(42,43)$ \\
\hline
\end{tabular}

Table 2. Same as Table 1 but this time the focus is on the regional mean characteristics of convective sources and transport times.

\begin{tabular}{|c|c|c|c|c|c|}
\hline & Africa & N. Asian-Pacific & S. Asian-Pacific & C. America & S. America \\
\hline CS-TTL parcels, \% & 10 & 22 & 50 & 6 & 5 \\
\hline Cloud Temperature, $\mathrm{K}\left(\mu_{1 / 2}, \sigma\right)$ & $201(200,8.6)$ & $205(205,9.5)$ & $206(206,8.7)$ & $204(204,8.3)$ & $203(203,7.4)$ \\
\hline Parcel potential temperature, $\mathrm{K}\left(\mu_{1 / 2}, \sigma\right)$ & $354(354,5.5)$ & $357(356,5.5)$ & $353(352,3.3)$ & $353(352,5.4)$ & $355(353,5.3)$ \\
\hline Transit-time, days $\left(\mu_{1 / 2}, \sigma\right)$ & $61(47,46)$ & $61(50,43)$ & $58(43,46)$ & $58(45,44)$ & $61(47,46)$ \\
\hline
\end{tabular}

\section{Results}

We use the CS-TTL trajectory ensembles to identify the source regions for transport of cloud air into the upper TTL and lower stratosphere. In order to characterise vertical transport across the TTL, we calculate the distribution of times for cloud air to reach its destination (i.e., the initial location of the back trajectory) or a particular level for the first time (in forward time). Finally, we determine the distribution of cloud air at its destination for different ranges of values for the transport times. Throughout the rest of this paper, we concentrate on those CS-TTL trajectories that are detrained during 2005 (65\% of the CS-TTL ensemble for both all-sky and clear-sky conditions). The remaining CS-TTL trajectories that have either detrained during 2004 or 2006 are discarded.

\subsection{Convective sources for transport of cloud air into the stratosphere}

\subsubsection{Horizontal distributions}

For each launch level $p$, we determine the distribution of convective sources, $\rho(\mathbf{r}, t)$, for transport of cloud air into the stratosphere. We do this by calculating the ratio of the number of CS-TTL trajectories that encounter a cloud within the grid-box located at $\mathbf{r}=(\lambda, \phi)$, where $\lambda$ is the longitude and $\phi$ is the latitude, and time interval $[t, t+\Delta t]$ to a normalisation factor, $N(\phi, \Delta t)$. The value of $N(\phi, \Delta t)$ depends on the latitude $\phi$ and is given by the product of the grid-box area relative to the area of the tropics, the time-length $\Delta t$, relative to the period concerned (here, 2005) and the total number of CS-TTL trajectories during this period. $N(\phi, \Delta t)$ denotes the expected number of trajectories that would encounter a cloud within a given grid-box, if all regions were acting as sources of equal strength uniformly during 2005 (see also Berthet et al. (2007) where a similar normalisation is employed). We choose this normalisation in order to measure the relative importance of different regions for transporting cloud air across the TTL.

Berthet et al. (2007) have previously considered the seasonal variations of the distribution of source regions for transport of air from the boundary layer to the tropopause region. Here, we focus on the density distribution of source regions for transport of cloud air across the TTL and consider both the seasonal ( $\Delta t=3$ months) and daily variations ( $\Delta t=1$ day, whereby each day starts at 00:00 UTC). The daily variations are useful to capture individual convective sources which can thereafter be classified according to their intensity. By employing a daily resolution we thus neglect any variations associated with the diurnal cycle. We resolve the source distribution on a $5^{\circ} \times 5^{\circ}$ longitude/latitude grid in order to obtain meaningful statistics.

Figure 4 shows the seasonal variations of the density distribution, $\rho_{100 \mathrm{hPa}}$, of the locations where trajectories have detrained from clouds and subsequently arrived at $100 \mathrm{hPa}$. The results are calculated from the ALLSKY- $\Delta T 0$ and CLRSKY- $\Delta T 0$ trajectory ensembles for boreal winter, spring, summer and fall seasons. The distribution of sources is characterized by strong geographical localization and is consistent with the well-known locations of deep tropical convection (see also e.g. Gettelman et al., 2002; Hatsushika and Yamazaki, 2003; Gettelman et al., 2004; Fueglistaler et al., 2004; Levine et al., 2007). During boreal winter, the local maxima are over central Africa, the southern AsianPacific and southern America. The same three regions are also prominent during the boreal spring and fall seasons, though other regions, such as the northern Asian-Pacific and 
Table 3. Same as Table 1 but this time the focus is on all four CS-TTL ensembles, obtained for transport in all-sky and clear-sky conditions.

\begin{tabular}{lcccc}
\hline & ALLSKY- $\Delta T 0$ & ALLSKY- $\Delta$ T5 & ALLSKY- $\Delta T-5$ & CLRSKY- $\Delta T 0$ \\
\hline Cloud Temperature, $\mathrm{K}\left(\mu_{1 / 2}, \sigma\right)$ & $205(205,9)$ & $203(203,8.3)$ & $206(206,9.5)$ & $196(195,5.6)$ \\
Parcel potential temperature, $\mathrm{K}\left(\mu_{1 / 2}, \sigma\right)$ & $354(353,4.7)$ & $353(352,3.5)$ & $356(354,6.3)$ & $359(358,3.6)$ \\
Transit-time, days $\left(\mu_{1 / 2}, \sigma\right)$ & $59(46,45)$ & $64(51,46)$ & $53(40,44)$ & $83(75,49)$ \\
\hline
\end{tabular}
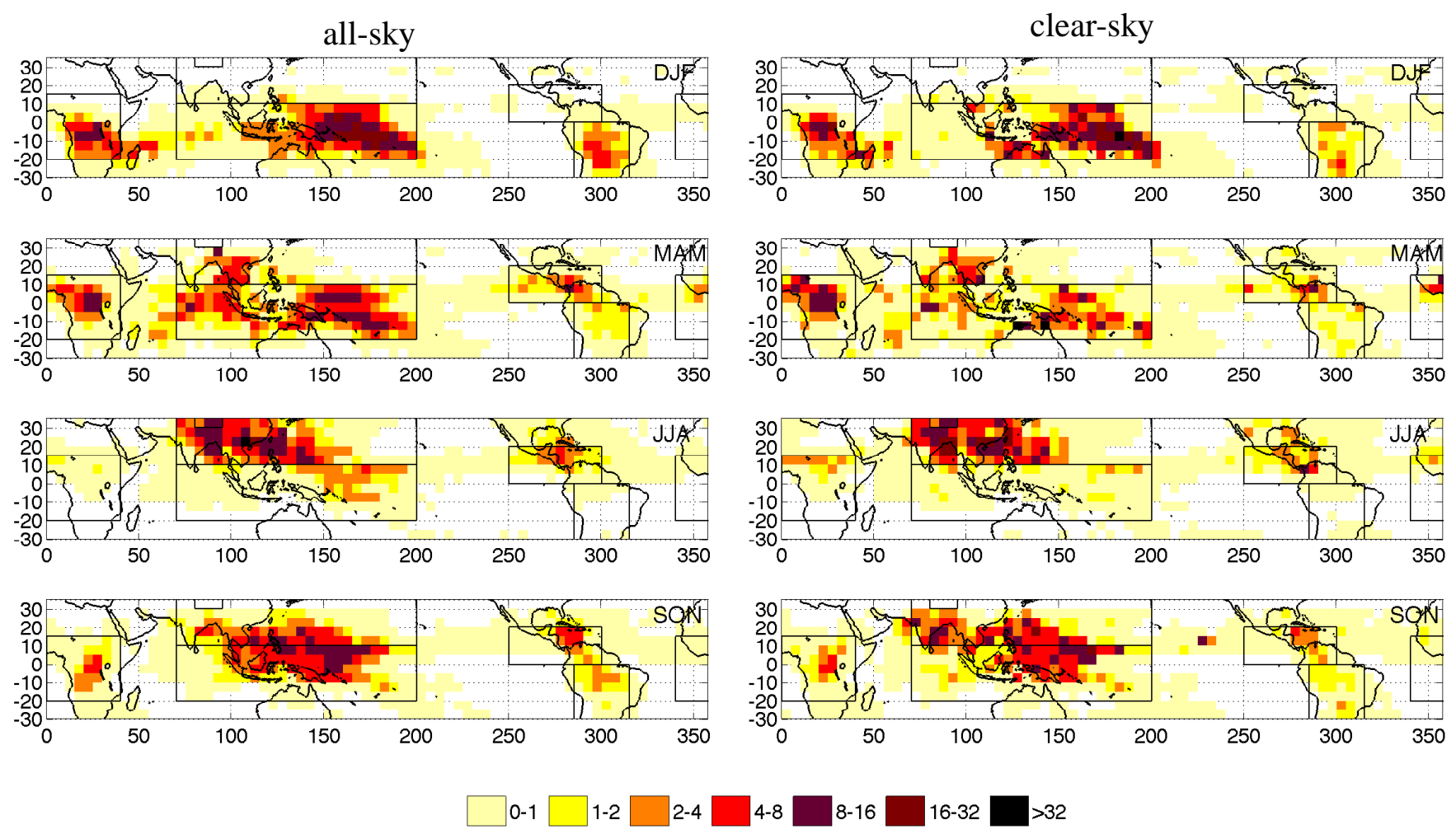

Fig. 4. Seasonal variations of the distribution $\rho_{100 \mathrm{hPa}}$ of the horizontal locations where trajectories, initially launched at $100 \mathrm{hPa}$, have intersected clouds within the previous 200 days for the boreal winter (DJF), spring (MAM), summer (JJA), and fall (SON) seasons in 2005. The distributions on the left panels are calculated under all-sky conditions from the ALLSKY- $\Delta T 0$ trajectory ensemble, while those on the right panels are calculated under clear-sky conditions, using the CLRSKY- $\Delta T 0$ ensemble. The distributions are binned in a $5^{\circ} \times 5^{\circ}$ longitude/latitude grid. The solid boxes define a set of geographical regions which are (from left to right): Af, NAP, NAPL, Tib, SAP, CAm and SAm as defined in Fig. 2.

equatorial America, also become important during this period. During boreal summer, most activity takes place over the northern Asian-Pacific and central America. Very similar distributions to the ones shown in Fig. 4 were also found for transport from clouds to the $70 \mathrm{hPa}$ surface as well as for shorter, 60-day long trajectories (not shown).

For both ALLSKY- $\Delta T 0$ and CLRSKY- $\Delta T 0$, we find that trajectories are detrained all along 2005 with a slight preference for the boreal winter and spring seasons (see Table 1 for results obtained from the ALLSKY- $\Delta T 0$ ensemble). Most CS-TTL trajectories have detrained within the southern Asian-Pacific region (50\% and $44 \%$ for all-sky and clear-sky conditions, respectively) while a significant proportion of CS-TTL trajectories has detrained within the north- ern Asian-Pacific (22\% and $27 \%$ ). A smaller percentage has detrained within Africa (10\% and $13 \%)$, and an even smaller part comes from central and southern America (3$6 \%$ for both regions and ensembles; see also Table 2). For both CS-TTL ensembles, the contribution from the Tibetan plateau remains small $(\lesssim 2.5 \%$ and $\lesssim 3.6 \%$ respectively, of the total and northern Asian-Pacific boreal summer convective sources). This result is in agreement with recent work by Park et al. (2007); James et al. (2008); Devasthale and Fueglistaler (2010); Wright et al. (2011) but does not support previous work by Fu et al. (2006) in which the contribution from the Tibetan plateau is found to be more important. The radiative influence of clouds leads to a noticeable difference $(5-6 \%)$ in the proportion of trajectories that are detrained by 
clouds within the Asian-Pacific region. However, this difference is smaller (within $\pm 3 \%$ ) in other regions.

Note that the difference in the regional proportions obtained from the ALLSKY- $\Delta T 0$, ALLSKY- $\Delta T 5$ and ALLSKY- $\Delta T-5$ ensembles is found to be at most $4 \%$ (not shown). The same is true for the regional proportions obtained from the ALLSKY- $\Delta T 0$ ensemble launched at $100 \mathrm{hPa}$ and $70 \mathrm{hPa}$.

\subsubsection{Localization of the horizontal distributions}

The distribution of convective sources is highly localized not only in space but also in time. The spatio-temporal localisation of the daily-varying $\rho(\mathbf{r}, t)$ can be analysed by considering the fraction of horizontal locations and times that have a density distribution whose value exceeds a given threshold, $\varrho$. More precisely, we define:

$\mathcal{A}(\varrho)=\frac{1}{\Omega} \int_{T} d t \int_{\sigma} d \mathbf{r} \mathcal{I}_{\varrho}(\mathbf{r}, t)$,

where $\mathcal{I}_{\varrho}$ is the indicator function:

$\mathcal{I}_{\varrho}(\mathbf{r}, t)=\left\{\begin{array}{l}1, \text { if } \rho(\mathbf{r}, t) \geq \varrho, \\ 0, \quad \text { otherwise, }\end{array}\right.$

and $\Omega$ denotes the total space-time volume. Its value is given by $\Omega=\int_{T} d t \int_{\sigma} d \mathbf{r} \mathcal{I}_{0}(\mathbf{r}, t)$, where $\sigma$ denotes the region in which the sources of convection are resolved (here, the tropics) and $T$ the time period concerned (here, the year 2005). It follows that $\mathcal{A}(0)=1$.

Thus, by considering increasingly large values of $\varrho$, we obtain the fraction of space-time volume associated with increasingly intense sources. The fraction of trajectories associated with $\mathcal{A}(\varrho)$ is given by

$P(\varrho)=\int \mathcal{I}_{\varrho}(\mathbf{r}, t) \rho(\mathbf{r}, t) d \mathbf{r} d t$.

By definition $\mathcal{A}(\varrho)$ is a monotonically decreasing function of $\varrho$ and thus there exists a unique inverse, $\varrho(\mathcal{A})$. Employing this inverse, we compose $P_{\varrho}(\mathcal{A}) \equiv(P \circ \varrho)(\mathcal{A})$. A function of the space-time volume, $P_{\varrho}(\mathcal{A})$ measures how localized the source distribution is. It can be shown that $P_{\varrho}(\mathcal{A})$ is a monotonically increasing function of $\mathcal{A}$ with $\lim _{\mathcal{A} \rightarrow 0} P_{\varrho}=0$ and $\lim _{\mathcal{A} \rightarrow 1} P_{\varrho}=1$. The value of $\mathcal{A}$ for which $P_{\varrho}(\mathcal{A})=0.5$ or 0.99 indicate the degree of localization of the distribution. The smaller their values are, the more localized is the source distribution.

We employ $P_{\varrho}(\mathcal{A})$ to measure how localised $\rho_{100 \mathrm{hPa}}$ is, as this varies daily. For comparison, $P_{\varrho}(\mathcal{A})$ is calculated for all four CS-TTL ensembles. Figure 5a shows that a very small (0.5-2\%) proportion of $\Omega$ accounts for half of the trajectories (associated with the most intense sources) and 3-8\% of $\Omega$ accounts for nearly all (99\%) of the CS-TTL trajectories. (Nearly identical distributions are obtained both for trajectories launched at $70 \mathrm{hPa}$ and for shorter, 60-day long trajectories). Note that the corresponding proportions are considerably larger for the distribution $\tilde{\rho}_{100 \mathrm{hPa}}$ obtained by uniformly

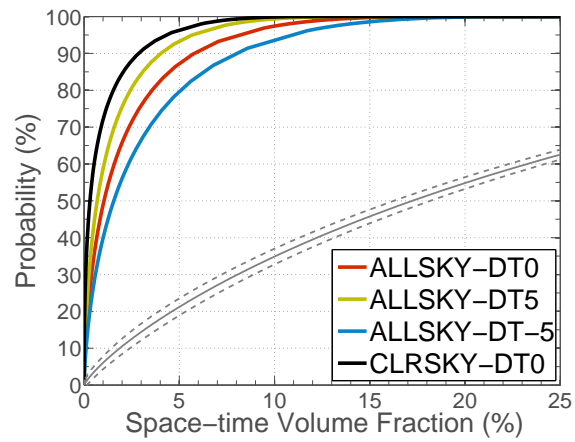

(a)

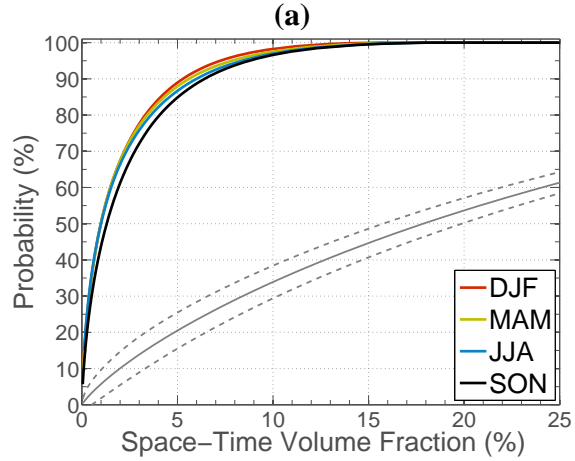

(b)

Fig. 5. Localization of the density distribution $\rho_{100 \mathrm{hPa}}$, as measured by the cumulative fraction $P_{\varrho}(\mathcal{A})$, defined in Eq. (3.1.2). (a) Ensemble characteristics of $P_{\varrho}(\mathcal{A})$ obtained from four CS-TTL trajectory ensembles, all launched at $100 \mathrm{hPa}$. (b) Seasonal characteristics of $P_{\varrho}(\mathcal{A})$ obtained from the ALLSKY- $\triangle T 0$ ensemble by considering trajectories detrained during boreal winter (DJF), spring (MAM), summer (JJA) and fall (SON) seasons in 2005. For both (a) and (b) are plotted the mean (solid grey) and mean \pm standard deviation (dotted grey) of $P_{\tilde{\varrho}}(\mathcal{A})$ obtained from 1000 realisations of $\tilde{\rho}_{100 \mathrm{hPa}}$ produced under uniform random conditions.

randomly distributing the same number of cloud encounters in $\Omega$ in both space and time.

The source distribution that is most localised is the one obtained under clear-sky conditions. The least localised distribution corresponds to the one obtained under all-sky conditions, having taken into account a thermal bias of $\Delta T=$ $-5 \mathrm{~K}$. This is consistent with the fact that the C-LZH is, on average, higher than the A-LZH, leading to a smaller number of sources that are able to detrain air at higher levels of the TTL. Conversely, under all-sky conditions, when the thermal bias becomes progressively smaller (from $\Delta T=5 \mathrm{~K}$ to $\Delta T=0$ and then $\Delta T=-5 \mathrm{~K}$ ), the top of clouds become progressively raised, leading to a larger number of sources that are able to detrain air at higher levels of the TTL.

We now employ $P_{\varrho}(\mathcal{A})$ to measure how the structure of $\rho_{100 \mathrm{hPa}}$ varies with the season. In this case, $\Omega$ denotes the total space-time volume during a particular season. Interestingly, the degree of source localisation varies very little with the season (see Fig. $5 \mathrm{~b}$ calculated from the ALLSKY- $\Delta T 0$ ensemble). 


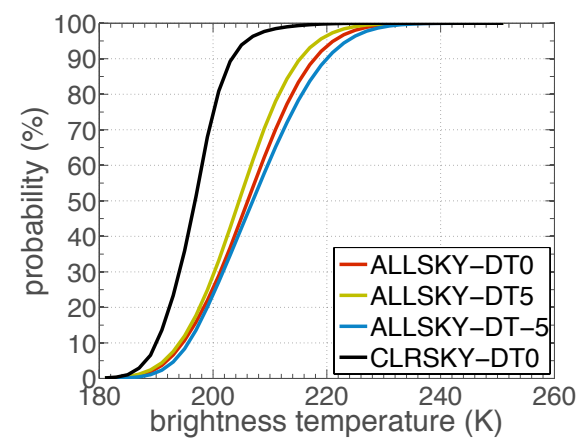

(a)

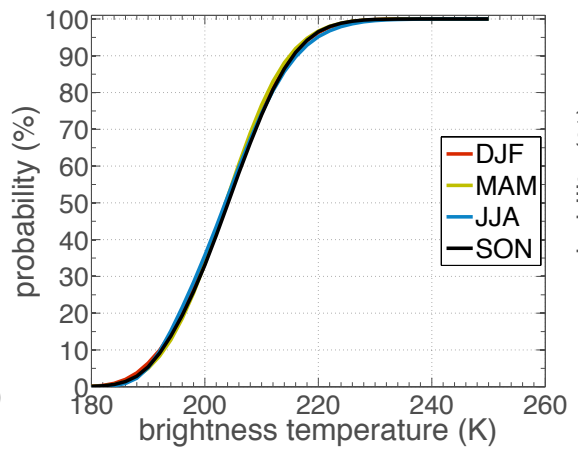

(b)

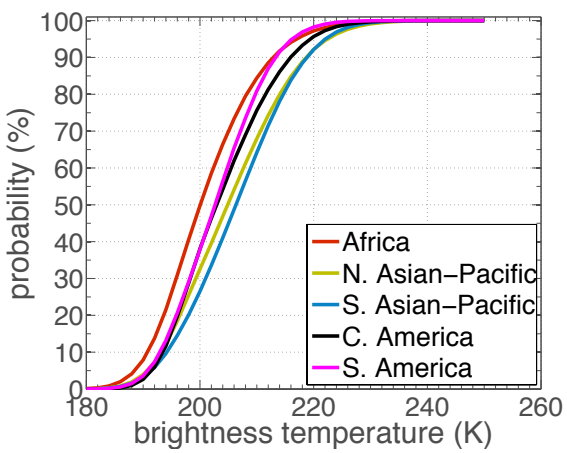

(c)

Fig. 6. Cumulative histograms of cloud top brightness temperatures for convective sources that transport air parcels to the $100 \mathrm{hPa}$ surface. (a) Results obtained for all-sky and clear-sky conditions, from ensembles ALLSKY- $\Delta T 0$, ALLSKY- $\triangle$ T5, ALLSKY- T -5 and CLRSKY$\triangle T 0$. (b) Results obtained for all-sky conditions only, from the ALLSKY- $\Delta T 0$ ensemble, for trajectories detrained during boreal winter (DJF), spring (MAM), summer (JJA) and fall (SON) seasons. (c) Results obtained for all-sky conditions only, from the ALLSKY- $\Delta T 0$ ensemble, for trajectories detrained in the region of Africa, north Asian-Pacific, south Asian-Pacific, central America and South America, designated in Fig. 2.

\subsubsection{Cloud top brightness temperatures}

The cumulative histograms of BT for the selected clouds encountered by the CS-TTL parcels are shown in Fig. 6a for the four trajectories ensembles, launched at $100 \mathrm{hPa}$ (the same results are obtained for simulations launched at $70 \mathrm{hPa}$ and for shorter, 60-day long trajectories). Nearly all (90\%) of the CS-TTL parcels have detrained from very deep clouds (with $\mathrm{BT} \leq 220 \mathrm{~K}$ and $\mathrm{BT} \leq 203 \mathrm{~K}$ for transport under all-sky and clear-sky conditions, respectively). As expected, the air parcels sample the deepest convective sources more efficiently in clear-sky than in all-sky conditions. This is because in all-sky conditions, the CS-TTL trajectories can be detrained from convective sources that have a broader range of brightness temperatures than in clear-sky conditions (recall that the mean A-LZH is lower than the mean C-LZH).

No seasonal variations are observed in the BT cumulative histograms (see Fig. 6b). However, some regional variations are present (see Fig. 6a) with the deepest convective sources located within the region of Africa, followed by the region of southern and central America (see also Table 2). These regional characteristics are consistent with previous observations which find that the deepest convective events occur predominantly over land, particularly above the region of Africa (see e.g. Liu and Zipser, 2005).

\subsubsection{Sparseness of the horizontal distributions among increasingly deep clouds}

It is interesting to construct a measure of how $\rho(\mathbf{r}, t)$ is distributed among the space occupied by clouds. For it is not clear that all sufficiently deep clouds will participate in the same way in troposphere-to-stratosphere transport. In particular, large-scale horizontal advection can transport cloud air that is detrained within a certain region into other regions where the LZH has a higher potential temperature, and subsequently may subside back into the troposphere (see also discussion in Devasthale and Fueglistaler, 2010). It can also be that the fast upward motion associated with radiative heating from clouds only occurs around a selected number of deep convective clouds. This is because cirrus clouds may either not be present or cloud air may subside due to the radiative cooling associated with that part of the cirrus that is situated directly above deep convective clouds (see Hartmann et al., 2001). Both these mechanisms could be significant in controlling how influential a convective source will be in transporting cloud air into the stratosphere.

To measure how sparsely distributed $\rho(\mathbf{r}, t)$ is within the space occupied by clouds, we employ $P_{\varrho \mid T^{*}}(\mathcal{A})$, a variant of $P_{\varrho}(\mathcal{A})$, introduced in Sect. 3.1.2, that describes how sparse the source distribution is in $\Omega_{T^{*}}$, where $\Omega_{T^{*}}$ is defined as the total space-time volume with brightness temperature, $B T \leq T^{*}$. We can thus define $\mathcal{A}$ as in Eq. (3.1.2) but this time in terms of $\Omega_{T^{*}}$ and $\mathcal{I}_{\varrho \mid T^{*}}$ where

$\mathcal{I}_{\varrho \mid T^{*}}(\mathbf{r}, t)= \begin{cases}1, & \text { if } \rho(\mathbf{r}, t) \geq \varrho \text { and } B T(r, t) \leq T^{*}, \\ 0, & \text { otherwise. }\end{cases}$

$P_{\varrho \mid T^{*}}(\mathcal{A})$ thus measures how the sources of transport to the stratosphere are distributed among convective systems that reach similar depths in the troposphere.

In order to calculate $P_{\varrho \mid T^{*}}(\mathcal{A})$, we resolve the sources on the same grid as the BT measurements (see Sect. 2.2). This resolution is of course too high for $P_{\varrho \mid T^{*}}(\mathcal{A})$ to converge to an invariant form that is insensitive to the frequency at which the trajectories are launched (note that this is not the case for $P_{\varrho}(\mathcal{A})$, shown in Fig. 5, which unlike $P_{\varrho \mid T^{*}}(\mathcal{A})$, is based on a significantly lower resolution in both space and time for the source distribution). It is nevertheless possible to assess the sparseness of the sources by considering the departure of $P_{\varrho \mid T^{*}}(\mathcal{A})$ from a reference $P_{\tilde{\varrho} \mid T^{*}}(\mathcal{A})$ with $\tilde{\varrho} \mid T^{*}$ obtained by 


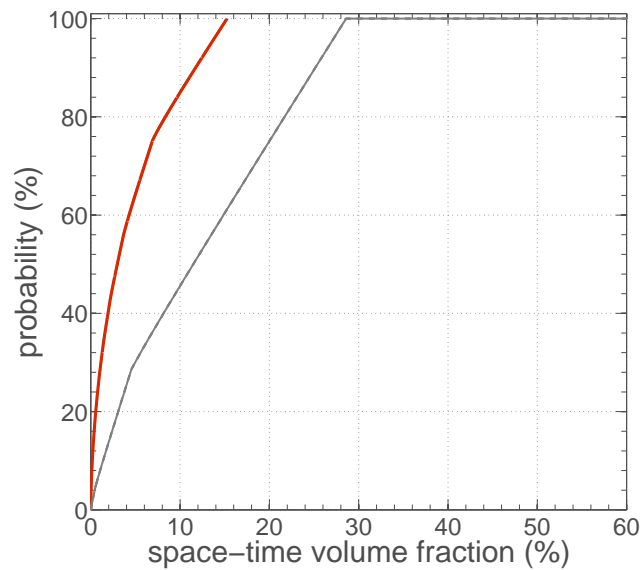

(a)

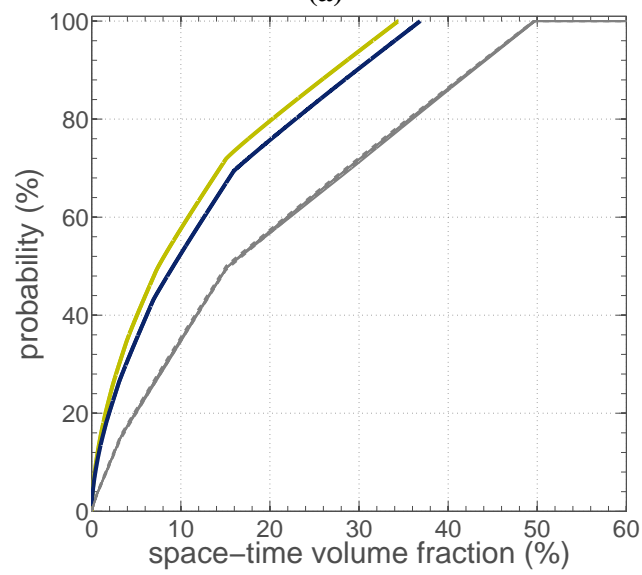

(b)

Fig. 7. Localization of horizontal distributions among sources of similar depth as measured by $P_{\varrho \mid T^{*}}(\mathcal{A})$ obtained for (a) $T^{*}=$ $215 \mathrm{~K}$ (red) and (b) $200 \mathrm{~K}$ (yellow) and $185 \mathrm{~K}$ (blue). Also plotted the mean (solid grey) and mean \pm standard deviation (dashed grey) of $P_{\tilde{\varrho}} \mid T^{*}(\mathcal{A})$ obtained from 1000 realisations of $\tilde{\rho}_{100 \mathrm{hPa}}$. The differences between the latter three curves is small for the range of values plotted here. The distributions are calculated for all-sky conditions, using the ALLSKY- $\triangle T 0$ ensemble launched at $100 \mathrm{hPa}$ (see text for more details).

uniformly randomly distributing the same number of cloud encounters among horizontal locations with $\mathrm{BT} \leq T^{*}$.

We consider three different BT threshold values, $T^{*}=$ 215,200 and $185 \mathrm{~K}$, and calculate $P_{\varrho \mid T^{*}}(\mathcal{A})$ from the ALLSKY- $\Delta T 0$ ensemble launched at $100 \mathrm{hPa}$. Figure 7 shows that the differences between $P_{\varrho \mid T^{*}}(\mathcal{A})$ and the mean of $P_{\tilde{\varrho} \mid T^{*}}(\mathcal{A})$, obtained from 1000 realisations of $\tilde{\varrho} \mid T^{*}$, are significant. These differences suggest that the transport of cloud air into the stratosphere is not equally distributed among clouds of similar cloud top BT. At the same time, the smaller the value of $T^{*}$ is, the deeper the clouds in $\Omega_{T^{*}}$ are and thus they can be sampled more easily. As a result, with decreasing $T^{*}, P_{\varrho \mid T^{*}}(\mathcal{A})$ becomes less sparse as the differences between $P_{\varrho \mid T^{*}}(\mathcal{A})$ and $P_{\tilde{\varrho} \mid T^{*}}(\mathcal{A})$ become smaller.
Note that in clear-sky conditions, the difference between $P_{\varrho \mid T^{*}}(\mathcal{A})$ and $P_{\tilde{\varrho} \mid T^{*}}(\mathcal{A})$ is larger (not shown). In these conditions, the number of CS-TTL parcels detrained from very deep clouds is larger than in all-sky conditions (see Fig. 6). Therefore, the corresponding statistics are closer to their invariant form. The latter suggests that the invariant form of $P_{\varrho \mid T^{*}}(\mathcal{A})$ is more sparse than in Fig. 7.

\subsubsection{Vertical distributions}

The histograms of the potential temperatures at which the CS-TTL trajectories encounter a cloud are shown in Fig. 8a for the four trajectory ensembles, launched at $100 \mathrm{hPa}$ (nearly identical results are obtained for trajectories launched at $70 \mathrm{hPa}$ and for shorter, 60-day long trajectories). Under allsky conditions, the histograms of these potential temperatures are mainly confined between 350 and $360 \mathrm{~K}$. For all $\Delta T$, no encounters of clouds take place below $340 \mathrm{~K}$ (i.e., all encounters take place above or near the mean level of maximum convective outflow). For $\Delta T=0,10 \%$ of the encounters occur above $360 \mathrm{~K}$ while only $4 \%$ occur above $365 \mathrm{~K}$. Under clear-sky conditions, the corresponding potential temperature histogram is narrower, with no cloud encounters taking place below $352 \mathrm{~K}$ while only $5 \%$ occurring above $366 \mathrm{~K}$.

In the absence of thermal biases (i.e., $\Delta T=0$ ), the mean potential temperature is equal to the mean $\mathrm{LZH}$ in both allsky and clear-sky cases (see also Table 3 ). When we consider a thermal bias of $\Delta T=-5 \mathrm{~K}$ (equivalent to raising cloud heights), the average is displaced by $2 \mathrm{~K}$ to a larger value of potential temperature. Conversely, a displacement of $1 \mathrm{~K}$ to a lower value is obtained when we consider a thermal bias of $\Delta T=5 \mathrm{~K}$ (equivalent to lowering cloud heights). Near the tropopause, $\Delta \theta \approx-2 \Delta T$. Thus, there is no direct relation between the mean displacement in potential temperature and the mean displacement in the cloud top height. We may speculate that the lack of an obvious such relation is a combination of the effect of a transport barrier (imposed by the LZH) and the rapid decrease of deep clouds with altitude (as observed from BT data). Upon application of a bias on the BTs, the barrier effect dominates the subsequent shift in the cloud top heights. This is, perhaps, the reason why the resulting shift in the vertical distribution of the sources is smaller than one would expect by solely looking at the shift in BTs.

Figure $8 \mathrm{~b}$ shows the seasonal variations of the potential temperature histograms obtained from the ALLSKY- $\Delta T 0$ ensemble, launched at $100 \mathrm{hPa}$. The potential temperatures are nearly identically distributed for CS-TTL parcels detrained during the boreal winter and spring season; during the autumn season, the histogram is similar but shifted to slightly lower values (see also Table 1). The main difference occurs for CS-TTL parcels detrained during the summer. In this case, the parcels' potential temperatures appear to have a histogram that has two peaks, the first peak being located at about $352 \mathrm{~K}$ and the second one at $358 \mathrm{~K}$. 


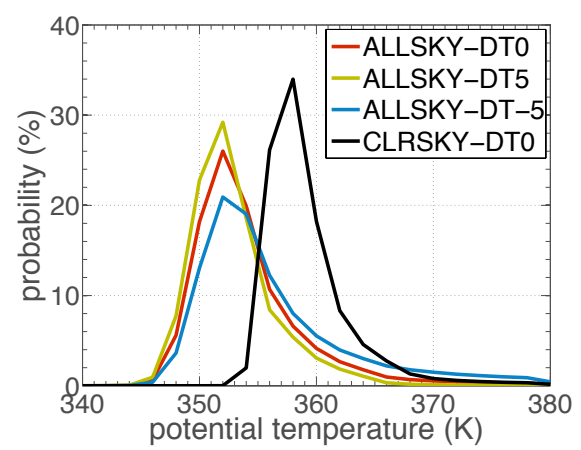

(a)

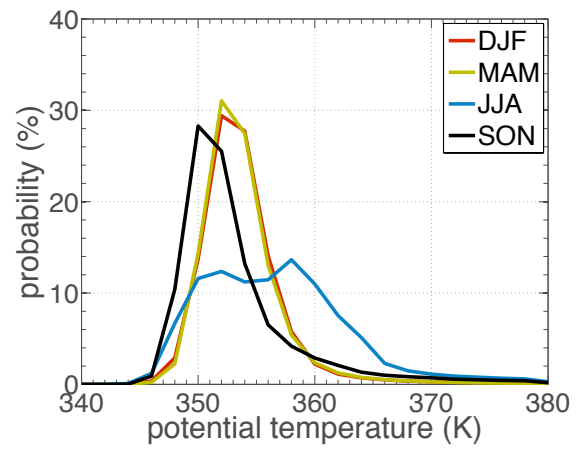

(b)

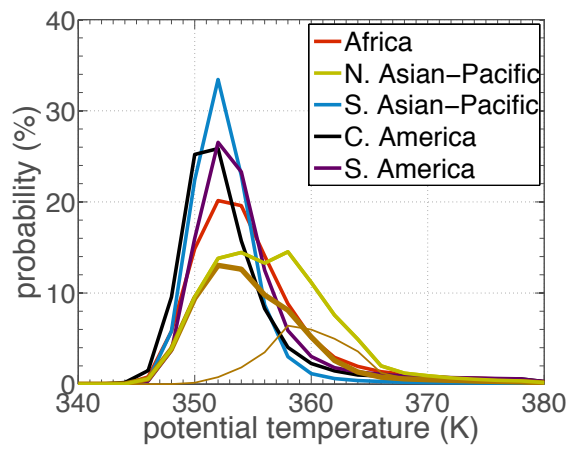

(c)

Fig. 8. Same as Fig. 6 but this time the focus is on the histograms of potential temperatures at which encounters with convective sources have taken place. Also shown in (c) are the histograms corresponding to trajectories detrained over the land (thin brown line) and ocean (thick brown line) parts of the north Asian-Pacific region (respectively defined as NAPL and NAPO in Fig. 2) The histograms are calculated using a bin size of $2 \mathrm{~K}$ in potential temperature.

A similar two-peak behaviour, albeit weaker, is observed for parcels detrained in the northern Asian-Pacific region which is mainly active during the summer season (see Fig. 8c). We find that the first peak is mainly due to detrainment over the ocean while the second peak is due to detrainment over the land part of the northern Asian-Pacific that can take place at latitudes higher than $20^{\circ} \mathrm{N}$. As shown in Fig. 2, during boreal summer, these two regions have very different profiles of heating rates: Over the ocean part of the northern Asian-Pacific (NAPO), the heating rate profile does not differ from the mean tropical average (see also Fig. 1a). Conversely, the differences are significant over the land part (NAPL) with both the C-LZH and the A-LZH being shifted upwards with this shift being more pronounced for the ALZH. Hence, at these higher latitudes, convection must reach higher to contribute to upward moving air across the TTL.

It is interesting to note that the above land-ocean differences are not reflected in the brightness temperatures of the corresponding convective sources. More generally, there is no direct relation between the mean potential temperature of cloud encounters and the mean brightness temperature of the corresponding convective sources (e.g. although the deepest convective sources occur more frequently in the region of Africa, the average height of cloud encounter within this region is not significantly different to the average height of cloud encounter in other regions, such as the southern Asian-Pacific region, in which, in general, convection does not reach as high (see also Sect. 3.1.3)).

Finally, we note that, in comparison to the case of all-sky radiative heating rates (with $\Delta T=0$ ), the use of total diabatic heating rates results in cloud encounters which are, on average, at potential temperatures that are lower by about $4 \mathrm{~K}$ (not shown).

\subsection{Timescales for transport of cloud air across the TTL and into the lower stratosphere}

\subsubsection{First-entry times}

We now focus on the time it takes for CS-TTL parcels to first enter (in forward time) the upper TTL and the stratospheric "overworld". Figure 9a shows the histograms of times for air of convective origin to first reach the $370 \mathrm{~K}$ and $380 \mathrm{~K}$ surfaces. The corresponding results obtained from the four trajectory ensembles, with destination at $100 \mathrm{hPa}$. Similar histograms are obtained for trajectories launched at $70 \mathrm{hPa}$ as well as for shorter, 60-day long trajectories (not shown). In both all-sky and clear-sky cases, the histograms are broad and skewed, decaying exponentially at large times.

The histograms obtained under all-sky conditions are characterized by a pronounced peak, located at approximately 15 days, that is largely unaffected by the variable offset $\Delta T$. Note that the location of the peak is consistent with the estimated time that Corti et al. (2006) obtained for cloud air to first reach the $370 \mathrm{~K}$ surface, provided it stays inside a cirrus for most of the time. Conversely, the corresponding histogram obtained for clear-sky conditions is notably broader, with a slower decay rate at large times.

The average time to first reach the $370 \mathrm{~K}$ surface is, depending on the value of $\Delta T$, between 23 and 31 days for allsky conditions and 54 days for clear-sky. The corresponding time for the $380 \mathrm{~K}$ surface is between 33 and 44 days for allsky conditions and 64 for clear-sky (see also Table 4). It is thus clear that the radiative heating associated with clouds significantly accelerates transport across the TTL.

The radiative influence of clouds on transport across the TTL is mainly confined to the region below the $360 \mathrm{~K}$ surface. This is evidenced in Fig. $9 \mathrm{~b}$ in which the histograms of times to cross the $360-370 \mathrm{~K}$ and $360-380 \mathrm{~K}$ layers are shown to be similar in all-sky and clear-sky conditions (note 


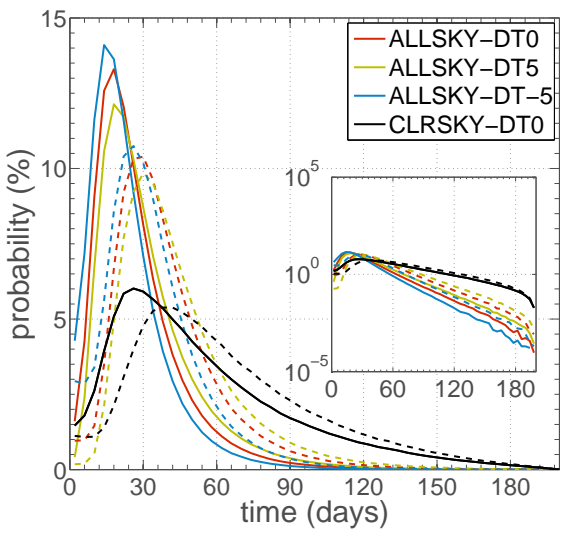

(a)

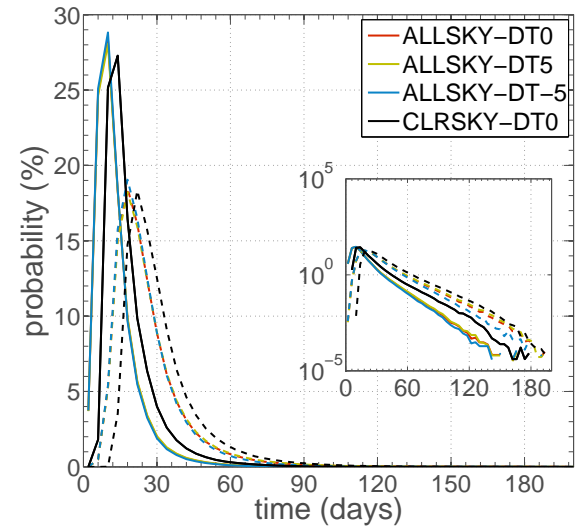

(b)

Fig. 9. Histograms showing (a) first-entry times of cloud air to the $370 \mathrm{~K}$ surface (solid) and $380 \mathrm{~K}$ surface (dotted) and (b) times for cloud air to cross the 360-370 K layer (solid) and 360-380,K layer (dotted). Results obtained for all-sky and clear-sky conditions from four CS-TTL trajectory ensembles, all launched at 100hPa. The histograms are calculated using a bin size of 4 days.

Table 4. Mean characteristics of the distributions of times for transport of cloud air out of the region below $360 \mathrm{~K}$ and into the $370 \mathrm{~K}$ and $380 \mathrm{~K}$ surface for the first time. Calculations made using the four CS-TTL trajectory ensembles, all launched at $100 \mathrm{hPa}$. The values for the median, $\mu_{1 / 2}$, and standard deviation, $\sigma$, are given in parenthesis.

\begin{tabular}{lcccc}
\hline & ALLSKY- $\Delta T 0$ & ALLSKY- $\Delta$ T5 & ALLSKY- $\Delta$ T-5 & CLRSKY- $\Delta T 0$ \\
\hline Exit-time from region below 360 K surface, days $\left(\mu_{1 / 2}, \sigma\right)$ & $15(11,16)$ & $19(13,19)$ & $12(9,13)$ & $42(32,37)$ \\
First entry into 370 K surface, days $\left(\mu_{1 / 2}, \sigma\right)$ & $27(23,18)$ & $31(26,20)$ & $23(20,16)$ & $54(45,37)$ \\
First entry into 380 K surface, days $\left(\mu_{1 / 2}, \sigma\right)$ & $39(35,22)$ & $44(39,23)$ & $33(30,20)$ & $64(56,37)$ \\
\hline
\end{tabular}

that to obtain these histograms we ignore those CS-TTL trajectories that never go below $360 \mathrm{~K}$ ). At the same time, these histograms are considerably narrower than the histograms shown in Fig. 9a. It thus follows that the large width of the first-entry times are due the large dispersion in the times to exit the region below $360 \mathrm{~K}$ (in forward time). This dispersion is more pronounced in the clear-sky case. For all-sky conditions and $\Delta T=0$, the mean exit time is 15 days while for clear-sky conditions it is 42 days.

It is interesting to note that the mean all-sky first-exit and first-entry times found here are consistent with simple estimates such as those shown in Fig. $1 \mathrm{~b}$ obtained for $\theta_{0} \approx 355 \mathrm{~K}$ (recall that in all-sky conditions, the mean potential temperature at which parcels detrain is $354 \mathrm{~K}$ ). Conversely, the corresponding means obtained under clear-sky conditions cannot be explained using these sort of estimates.

We may thus conclude that the large width of the firstentry time histograms are a result of the combined effect of the radiative heating rates and horizontal motion around the LZH (whose mean level in the tropics coincides with the mean potential temperature at which the CS-TTL parcels are detrained in both clear- and all-sky conditions; see also Table 3). Horizontal motion can lead air parcels to alternate regions situated just below and above the LZH (equivalent to alternate regions of negative and positive heating rates), so that the air parcels respectively descend and rise. The corresponding variations in the vertical velocities impede the immediate ascent of a number of air parcels to higher altitudes. This is particularly true for clear-sky conditions: Without the radiative influence of cirrus clouds, the magnitudes of the vertical velocities are in general smaller than in all-sky conditions. As a result, parcels that are detrained below the mean C-LZH have less possibilities to escape to regions, sufficiently above the mean $\mathrm{C}-\mathrm{LZH}$, where the mean flow is strong and ascending. When this happens, the mean flow regains control over their vertical transport and the dispersion in the vertical motion becomes smaller. This indeed explains why the histograms in Fig. 9b are narrower than those in Fig. 9a. Note that the possibility of long trapping times near the LZH and in particular the C-LZH has first been reported in an idealized study by Sherwood and Dessler (2003). The existence of this so-called "stagnation region" has also been observed in several trajectory studies (e.g. Fueglistaler et al. (2004); Ploeger et al. (2010)). The presence of a "stagnation region" also explains the large number of "free" trajectories (i.e., trajectories that have not detrained from a convective source) which are found near the C-LZH (see Sect. 2.4). 


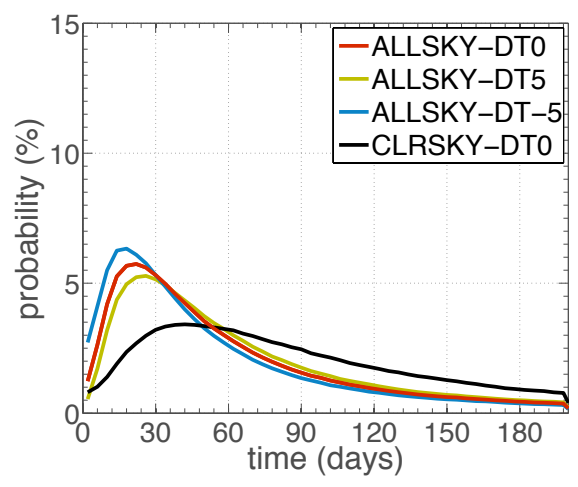

(a)

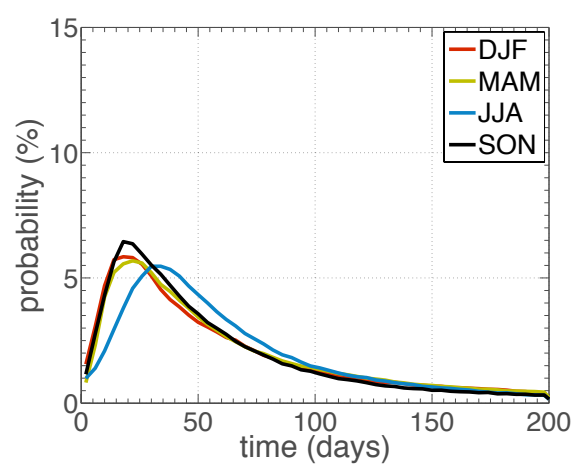

(b)

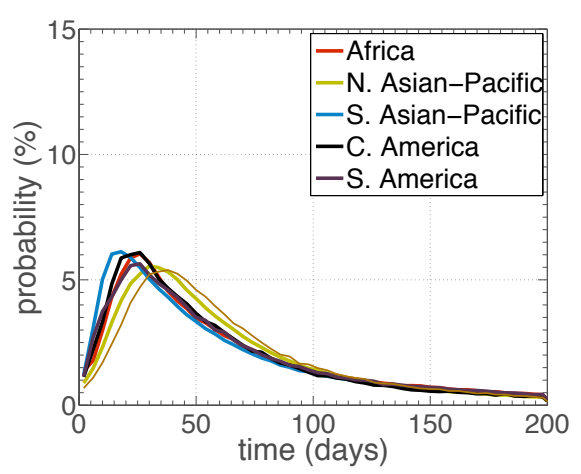

(c)

Fig. 10. (a) Ensemble, (b) seasonal and (c) regional histograms of transit-times between detrainment and launch at the $100 \mathrm{hPa}$ surface. Also shown in (c) the corresponding histogram for those trajectories detrained over the land part of the north Asian-Pacific region (brown line). Results obtained from the CS-TTL trajectory ensemble ALLSKY- $\Delta T 0$. The histograms are calculated using a bin size of 4 days.

\subsubsection{Transit-times}

The ensemble histograms of transit-times between detrainment and launch are shown in Fig. 10a for air parcels launched at $100 \mathrm{hPa}$. The longer times necessary for the air parcels to reach their destinations (in forward time) at higher latitudes is responsible for the larger width of the histograms (compare with the histograms shown in Fig. 9a). The mean transit-time is between 53 and 64 days for all-sky conditions and 83 days for clear-sky (see also Table 3).

Figure 10b-c shows the seasonal and regional dependence of transit-times. During boreal summer, air parcels are relatively slower in reaching their destination on the $100 \mathrm{hPa}$ surface: only $12 \%$ of cloud air detrained during that season reaches its destination on the $100 \mathrm{hPa}$ surface within 20 days which is about half the amount obtained during the other seasons. Similarly, air parcels detrained within the northern Asian-Pacific region (that is mainly active during boreal summer), particularly those detrained over land, are slow to reach their destination on the $100 \mathrm{hPa}$ surface: $15 \%$ of cloud air arrives within 20 days. This is to be contrasted with $25 \%$ of air parcels detrained in the southern Asian-Pacific region in which early transport is the fastest (see Fig. 10b). These differences are despite the higher potential temperatures at which air parcels detrain during both boreal summer and the northern Asian-Pacific region (see Fig. 8). Their slow ascent into the upper TTL is the combined result of the monsoon anticyclone that dominates the large-scale boreal summer circulation within this region and the smaller, on average, tropical radiative heating rates above approximately $365 \mathrm{~K}$ in comparison to the other seasons (see e.g. Fig. 2).

Finally, we note that, in comparison to the case of allsky radiative heating rates (with $\Delta T=0$ ), the use of total diabatic heating rates results in first-entry and transit-times which are, on average, shorter by about 4 days (not shown).

\subsection{Distribution of cloud air in the lower stratosphere}

The extensive large-scale horizontal motion that takes place within the TTL (Holton and Gettelman, 2001; Fueglistaler et al., 2004; Bonazzola and Haynes, 2004) ensures that, at the lower stratosphere (at about $100 \mathrm{hPa}$ ), air of convective origin is, in general, well-mixed in the longitude. The histograms, $\chi(r, \tau)$, of the destination (in forward time) of the CS-TTL trajectories differ according to the range of values of their transit-times.

We determine $\chi(r, \tau)$ by calculating the ratio of the number of CS-TTL trajectories, detrained during a certain season, located within the grid-box at $r$ and transit-times within $[\tau, \tau+\Delta \tau]$ to a normalization factor, $\tilde{N}(\phi, \Delta \tau)$. We choose a similar normalization to the one employed for $\rho(\mathbf{r}, t)$ in Sect. 3.1.1: The value of $\tilde{N}(\phi, \Delta \tau)$ depends on the latitude $\phi$ and is given by the product of the grid-box area relative to the area of launch surface $\left(50^{\circ} \mathrm{S}, 50^{\circ} \mathrm{N}\right)$, the transit-time length, $\Delta \tau$, relative to the maximum possible transit-time (here, 200 days) and the total number of CS-TTL trajectories detrained during the season concerned. The value of $\tilde{N}(\phi, \Delta \tau)$ denotes the expected number of CS-TTL trajectories that would be found within a grid-box if all CS-TTL trajectories had encountered a convective source with equal probability during the last 200 days (the length of the trajectories).

Figure 11 shows $\chi_{100 \mathrm{hPa}}$ calculated from the ALLSKY$\Delta T 0$ trajectory ensemble, launched at $100 \mathrm{hPa}$, for trajectories detrained during boreal winter (DJF) and summer (JJA). For both seasons we can identify three spatial regimes for $\chi(r, \tau)$. For small transit times $(\tau \lesssim 15$ days), the distribution of the CS-TTL parcels at the $100 \mathrm{hPa}$ surface are localized, with the local maxima located at or near the convective source regions (see also Fig. 4). This regime corresponds to about a tenth of the CS-TTL parcels (13 and $7 \%$ for parcels detrained during DJF and JJA, respectively). For intermediate transit-times ( $\tau \approx 15-60$ days), the distributions of the CS-TTL parcels are quasi-homogeneous within nearly the 

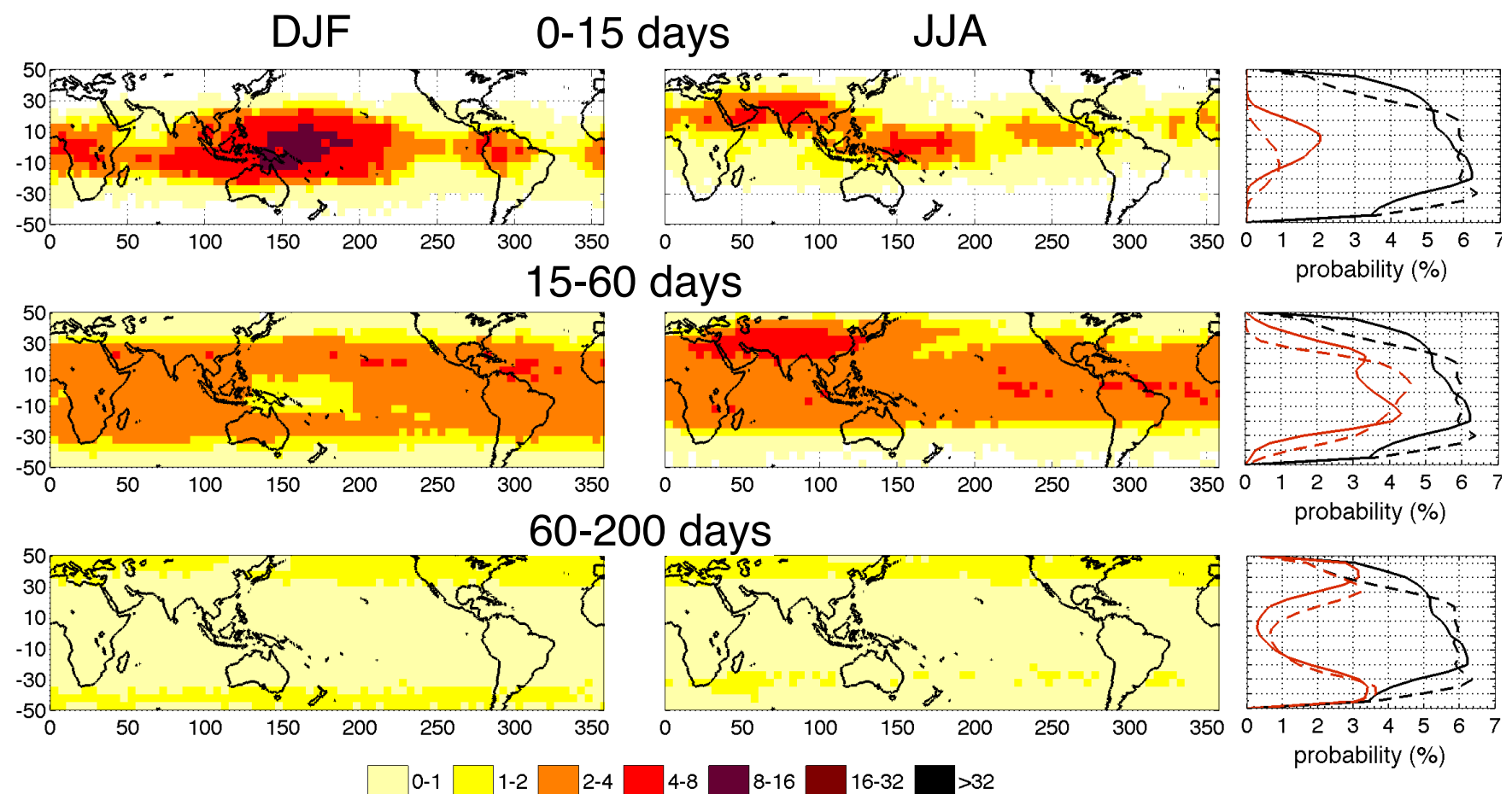

Fig. 11. Distribution, $\chi_{100 \mathrm{hPa}}$, of the horizontal locations of trajectories that have intersected clouds within the previous 15 days (top), between 15 and 60 days (middle) and between 60 and 200 days (bottom) on the $100 \mathrm{hPa}$ launch surface. The distributions are calculated for trajectories detrained during the 2005 boreal winter (left) and boreal summer (middle) using the ALLSKY- $\Delta T 0$ trajectory ensemble. The distributions are binned in a $5^{\circ} \times 5^{\circ}$ longitude/latitude grid and the histograms are calculated using a bin size of 5 degrees. The corresponding histograms showing the latitudinal position of CS-TTL trajectories detrained during boreal winter (solid) and summer (dashed) on the $100 \mathrm{hPa}$ surface, both the total (in black) and for different ranges of values for the transit-times, $\tau$ (in red).

whole $100 \mathrm{hPa}$ surface between the tropics $\left(30^{\circ} \mathrm{S}, 30^{\circ} \mathrm{N}\right)$. Notice the appearance of a local maximum in the region in which the monsoon anticyclone dominates during boreal summer. This is because air parcels are temporarily trapped by the monsoon anticyclone. Conversely, during boreal winter, the region over the southern Asian-Pacific (particularly the regions of Indonesia and western Pacific) are characterized by rapid ascent (see e.g. Fig. 10) and consequently no such maximum exists. This intermediate regime corresponds to about half of the CS-TTL parcels (49 and 52\% for parcels detrained during DJF and JJA, respectively). For large transit-times ( $\tau \approx 60-200$ days), the CS-TTL parcels are mostly present in the extra-tropics, within which they are quasi-homogeneously distributed. This regime corresponds to about four tenths of the CS-TTL parcels (38 and $41 \%$ respectively, for parcels detrained during DJF and JJA).

\section{Conclusions}

Previous considerations (Corti et al., 2005, 2006; Yang et al., 2010) have suggested that the radiative heating from cirrus clouds could play an important role in transporting air across the C-LZH -a barrier for vertical transport which must be overcome for air of convective origin to eventually reach the upper TTL and lower stratosphere. In this study, we have employed a novel Lagrangian approach that combines a large number of diabatic back trajectory calculations (in both clear-sky and all-sky conditions) with global fields of brightness temperatures in order to analyse the combined effect of cloud heating and large-scale horizontal motion on the transport of air across the TTL. The result is a quantitative picture of the seasonal and regional characteristics of convective sources and times for transport of air into the upper TTL and lower stratosphere.

We have shown that the lower, on average, level of A-LZH (in which the radiative heating of clouds is included) and the larger, in general, heating rates, both associated with cirrus clouds, facilitate the rapid upwelling of air across the TTL. Focusing on the ensemble of trajectories that have encountered a source of convection during 2005, we find that the majority of the trajectories that reach the upper TTL have encountered a source of convection near the mean A-LZH. The fluctuating nature of the latter combined with horizontal motion in this region result in a large dispersion in the vertical transport times which is reflected in the corresponding time distributions that are both wide and skewed (albeit less wide than the distributions obtained in clear-sky conditions). 
The mean time to first reach the $370 \mathrm{~K}$ surface is $\approx 27$ days, which is half the time obtained under clear-sky conditions. The distribution has a pronounced peak that is located at $\approx 15$ days. The latter time is consistent with the estimate that Corti et al. (2006) obtained for air of deep convective origin to ascent (with the help of cirrus) to the $370 \mathrm{~K}$ surface. We find that the time distributions are largely insensitive to a bias of about $\pm 1 \mathrm{~km}(\mp 5 \mathrm{~K})$ in the cloud top heights with the mean times shifted by about $\mp 4$ days.

The combination of a fluctuating A-LZH and horizontal motion near this barrier could also explain why some sources of convection are more successful than other equally deepreaching sources in transporting air into the upper TTL. We have deduced this uneven participation using a diagnostic that measures the localisation of the sources within the space they occupy.

Conversely, the strong horizontal motion within the TTL ensures that the majority of air of convective origin is wellmixed within the tropical lower stratosphere (for air detrained within the last 15-60 days) and the extra-tropical lower stratosphere (for air detrained more than 60 days ago). The small fraction $(\approx 10 \%)$ of air that has been detrained within the last 15 days is located above regions that lie in the neighbourhood of the convective sources. The distributions of transit times to the lower stratosphere exhibit some seasonal and regional characteristics but beyond 60 days they all decay uniformly exponentially with time.

The trajectory-based methodology that we have here employed provides a new way to quantify the sources of convection for large-scale transport into the upper TTL and lower stratosphere. It has two main advantages over other Lagrangian models. Firstly, the use of brightness temperatures to detect convection means that it is not necessary to resolve the fast convective updrafts that would otherwise need to be parameterised. Secondly, the use of radiative heating rates to represent vertical motion out of convection means that the descending trajectory motions associated with cloud-free regions between deep convective clouds are represented. It would be interesting to compare our results with corresponding results obtained in other Lagrangian models such as the one employed in Pisso et al. (2010) in which a convective parameterisation is taken into account and found to have a large impact on the ozone depletion potentials for VSLS.

The most important limitation of this work concerns the realism of the radiative heating rates in the ERA-Interim reanalysis dataset. As already noted, uncertainty in their values arises mostly due the influence of clouds. Despite this uncertainty, we believe that motion near the A-LZH will continue to depend on its fluctuating structure as the accuracy in the values of the radiative heating rates increases. Further work will require the comparison with radiative calculations performed using real distribution of clouds, as diagnosed, e.g. by CloudSat/CALIPSO (Sassen et al., 2008; Martins et al., 2011).
During the course of the revision of this work, we became aware of independent work by Bergman et al. (2011) which addresses similar questions and has obtained a number of results which are, to a large extent, comparable to some of the results presented here. There are some noticeable discrepancies regarding results obtained during the boreal summer season that might be due to differences in the heating rates (see also Wright et al. (2011) where some sensitivity to the underlying dataset is found), which is another motivation to further investigate this question in the future.

Acknowledgements. The authors thank G. Berthet, M. Bolot, J.-P. Duvel, S. Fueglistaler, P. H. Haynes, T.-Y. Koh and S. Y. Liu for useful discussions as well as three anonymous referees for their constructive comments. The results were obtained using ERA-Interim data, provided by the ECMWF, and the CLAUS archive, held at the British Atmospheric Data Centre (BADC) and produced using source data from the ISCCP that are made available at the NASA Langley Atmospheric Sciences Data Center (LASDC). A. Tzella acknowledges financial support from the Marie Curie Individual fellowship HydraMitra No. 221827.

Edited by: P. Haynes

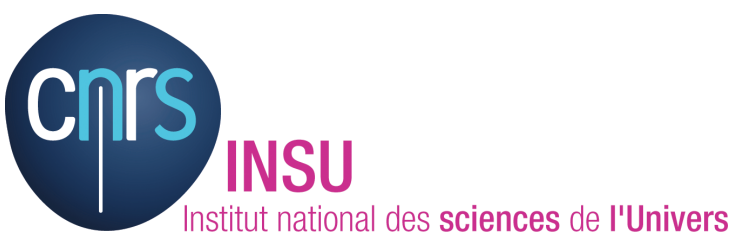

The publication of this article is financed by CNRS-INSU.

\section{References}

Bergman, J. W., Jensen, E. J., Pfister, L., and Yang Q.: Seasonal differences of vertical-transport efficiency in the tropical tropopause layer: On the interplay between tropical deep convection, largescale vertical ascent, and horizontal circulations, J. Geophys Res., submitted, 2011.

Berthet, G., Esler, J. G., and Haynes, P. H.: A Lagrangian perspective of the tropopause and the ventilation of the lowermost stratosphere, J. Geophys. Res., 112, D18102, doi:10.1029/2006JD008295, 2007.

Bonazzola, M. and Haynes, P. H.: A trajectory-based study of the tropical tropopause region, J. Geophys. Res., 109, D20112, doi:10.1029/2003JD004356, 2004.

Corti, T., Lup, B. P., Peter, T., Vömel, H., and Fu, Q.: Mean radiative energy balance and vertical mass fluxes in the equatorial upper troposphere and lower stratosphere, Geophys. Res. Lett., 32, L06802, doi:10.1029/2004GL021889, 2005.

Corti, T., Luo, B. P., Fu, Q., Vömel, H., and Peter, T.: The impact of cirrus clouds on tropical troposphere-to-stratosphere transport, Atmos. Chem. Phys., 6, 2539-2547, doi:10.5194/acp-6-25392006, 2006.

Dee, D. P., Uppala, S. M., Simmons, A. J., Berrisford, P., Poli, P., Kobayashi, S., Andrae, U., Balmaseda, M. A., Balsamo, G., Bauer, P., Bechtold, P., Beljaars, A. C. M., van de Berg, L., Bid- 
lot, J., Bormann, N., Delsol, C., Dragani, R., Fuentes, M., Geer, A. J., Haimberger, L., Healy, S. B., Hersbach, H., Hólm, E. V., Isaksen, L., Kållberg, P., Köhler, M., Matricardi, M., McNally, A. P., Monge-Sanz, B. M., Morcrette, J.-J., Park, B.-K., Peubey, C., de Rosnay, P., Tavolato, C., Thépaut, J.-N., and Vitart, F.: The ERA-Interim reanalysis: configuration and performance of the data assimilation system, Q. J. Roy. Meteorol. Soc., 137, 553597, doi:10.1002/qj.828, 2011.

Devasthale, A. and Fueglistaler, S.: A climatological perspective of deep convection penetrating the TTL during the Indian summer monsoon from the AVHRR and MODIS instruments, Atmos. Chem. Phys., 10, 4573-4582, doi:10.5194/acp-10-45732010, 2010.

Folkins, I., Lowenstein, M., Podolske, J. R., Oltmans, S. J., and Proffitt, M.: A barrier to vertical mixing at $14 \mathrm{~km}$ in the tropics: Evidence from ozonesondes and aircraft measurements, J. Geophys. Res., 104, 22095-22102, doi:10.1029/1999JD900404, 1999.

$\mathrm{Fu}, \mathrm{Q}$., Hu, Y., and Yang, Q.: Identifying the top of the tropical tropopause layer from vertical mass flux analysis and CALIPSO lidar cloud observations, Geophys. Res. Lett., 34, L14813, doi:10.1029/2007GL030099, 2007.

Fu, Y., Liu, G., Wu, G., Yu, R., Xu, Y., Wang, Y., Li, R., and Liu, Q.: Tower mast of precipitation over the central Tibetan Plateau summer, Geophys. Res. Lett., 33, L05802, doi:10.1029/2005GL024713, 2006.

Fueglistaler, S., Wernli, H., and Peter, T.: Tropical troposphereto-stratosphere transport inferred from trajectory calculations, J. Geophys. Res., 109, D03108, doi:10.1029/2003JD004069, 2004.

Fueglistaler, S., Bonazzola, M., Haynes, P. H., and Peter, T.: Stratospheric water vapor predicted from the Lagrangian temperature history of air entering the stratosphere in the tropics, J. Geophys. Res., 110, D08107, doi:10.1029/2004JD005516, 2005.

Fueglistaler, S., Dessler, A. E., Dunkerton, T. J., Folkins, I., Fu, Q., and Mote, P. W.: Tropical tropopause layer, Rev. Geophys., 47, RG1004, doi:10.1029/2008RG000267, 2009a.

Fueglistaler, S., Legras, B., Beljaars, A., Morcrette, J.-J., Simmons, A., Tompkins, A. M., and Uppala, S.: The diabatic heat budget of the upper troposphere and lower/mid stratosphere in ECMWF reanalyses, Q. J. Roy. Meteorol. Soc., 135, 21-37, doi:10.1002/qj.361, 2009b.

Gettelman, A. and de Forster, P. M.: Definition and climatology of the tropical tropopause layer, J. Meteorol. Soc. Jpn., 80, 911924, 2002

Gettelman, A., Salby, M. L., and Sassi, F.: Distribution and influence of convection in the tropical tropopause region, J. Geophys. Res., 107, 4080, doi:10.1029/2001JD001048, 2002.

Gettelman, A., de Forster, P. M., Fujiwara, M., Fu., Q., Vömel, H., Gohar, L. K., Johanson, C., and Ammerman, M.: Radiation balance of the tropical tropopause layer, J. Geophys. Res., 109, D07103, doi:10.1029/2003JD004190, 2004.

Hatsushika, H. and Yamazaki, K.: Stratospheric drain over Indonesia and dehydration within the tropical tropopause layer diagnosed by air parcel trajectories, J. Geophys. Res., 108, D194610, doi:10.1029/2002JD002986, 2003.

Hartmann, D. L., Holton, J. R., and Fu, Q.: The heat balance of the tropical tropopause, cirrus, and stratospheric dehydration, Geophys. Res. Lett., 28, 1969-1972, doi:10.1029/2000GL012833,
2001.

Highwood, E. J. and Hoskins, B. J.: The tropical tropopause, Q. J. Roy. Meteorol. Soc., 124, 1579-1604, doi:10.1002/qj.49712454911, 1998.

Hodges, K., D., Chappell, W., Robinson, G. J., and Yang, G.: An Improved Algorithm for Generating Global Window Brightness Temperatures from Multiple Satellite Infrared Imagery, J. Atmos. Ocean. Technol., 17, 1296-1312, doi:10.1175/15200426(2000)017;1296:AIAFGG;2.0.CO;2, 2000.

Holton, J. R. and Gettelman, A.: Horizontal transport and the dehydration of the stratosphere, Geophys. Res. Lett., 28, 2799-2802, doi:10.1029/2001GL013148, 2001.

Holton, J. R., Haynes, P. H., McIntyre, M. E., Douglass, A. R., Rood, R. B., and Pfister, L.: Stratosphere-troposphere exchange, Rev. Geophys., 33, 403-439, doi:10.1029/95RG02097, 1995.

James, R., Bonazzola, M., Legras, B., Surbled, K., and Fueglistaler, S.: Water vapor transport and dehydration above convective outflow during Asian monsoon, Geophys. Res. Lett., 35, L20810, doi:10.1029/2008GL035441, 2008.

Konopka, P., Groo $\beta$, Plöger, F., and Müller, R.: Annual cycle of horizontal in-mixing into the lower tropical stratosphere, J. Geophys. Res., 114, D19111, doi:10.1029/2009JD011955, 2009.

Levine, J. G., Braesicke, P., Harris, N. R. P., Savage, N. H., and Pyle, J. A.: Pathways and timescales for troposphere-tostratosphere transport via the tropical tropopause layer and their relevance for very short lived substances, J. Geophys. Res., 112, D04308, doi:10.1029/2005JD006940, 2007.

Liu, C. and Zipser, E. J.: Global distribution of convection penetrating the tropical tropopause, J. Geophys. Res., 110, D23104, doi:10.1029/2005JD006063, 2005.

Liu, Y. S., Fueglistaler, S., and Haynes, P. H.: The advectioncondensation paradigm for stratospheric water vapour., J. Geophys. Res., 115, D24307, doi:10.1029/2010JD014352, 2010.

Martins, E., Noel, V., and Chepfer, H.: Properties of cirrus and subvisible cirrus from nighttime Cloud-Aerosol Lidar with Orthogonal Polarization (CALIOP), related to atmospheric dynamics and water vapor, J. Geophys. Res., 116, D02208, doi:10.1029/2010JD014519, 2011.

Massie, S., Gettelman, A., W., R., and Baumgardner, D.: Distribution of tropical cirrus in relation to convection, J. Geophys. Res., 113, 4591, doi:10.1029/2001JD001293, 2002.

Monge-Sanz, B. M., Chipperfield, M. P., Simmons, A. J., and Uppala, S. M.: Mean age of air and transport in a CTM: Comparison of different ECMWF analyses, Geophys. Res. Lett., 34, L04801, doi:10.1029/2006GL028515, 2007.

Nawrath, S.: Water vapor in the tropical upper troposphere: On the influence of deep convection., Ph.D. thesis, Universität Köln, Germany, 2002.

Park, S., Jimnez, R., Daube, B. C., Pfister, L., Conway, T. J., Gottlieb, E. W., Chow, V. Y., Curran, D. J., Matross, D. M., Bright, A., Atlas, E. L., Bui, T. P., Gao, R.-S., Twohy, C. H., and Wofsy, S. C.: The $\mathrm{CO}_{2}$ tracer clock for the Tropical Tropopause Layer, Atmos. Chem. Phys., 7, 3989-4000, doi:10.5194/acp-7-39892007, 2007.

Pisso, I. and Legras, B.: Turbulent vertical diffusivity in the sub-tropical stratosphere, Atmos. Chem. Phys., 8, 697-707, doi:10.5194/acp-8-697-2008, 2008.

Pisso, I., Haynes, P. H., and Law, K. S.: Emission location dependent ozone depletion potentials for very short-lived 
halogenated species, Atmos. Chem. Phys., 10, 12025-12036, doi:10.5194/acp-10-12025-2010, 2010.

Ploeger, F., Konopka, P., Günther, G., Grooß, J.-U., and Müller, R.: Impact of the vertical velocity scheme on modeling transport in the tropical tropopause layer, J. Geophys. Res., 115, doi:10.1029/2009JD012023, 2010.

Ploeger, F., Fueglistaler, S., Grooß, J.-U., Günther, G., Konopka, P., Liu, Y. S., Müller, R., Ravegnani, F., Schiller, C., Ulanovski, A., and Riese, M.: Insight from ozone and water vapour on transport in the tropical tropopause layer (TTL), Atmos. Chem. Phys., 11, 407-419, doi:10.5194/acp-11-407-2011, 2011.

Sassen, K., Wang, Z., and Liu, D.: Global distribution of cirrus clouds from CloudSat/Cloud-Aerosol Lidar and Infrared Pathfinder Satellite Observations (CALIPSO) measurements, J. Geophys. Res., 113, D00A12, doi:10.1029/2008JD009972, 2008.

Schiller, C., Grooss, J.-U., Konopka, P., Plöger, F., Silva dos Santos, F. H., and Spelten, N.: Hydration and dehydration at the tropical tropopause, Atmos. Chem. Phys., 9, 9647-9660, doi:10.5194/acp-9-9647-2009, 2009.

Schoeberl, M. R., Douglass, A. R., Zhu, Z., and Pawson, S.: A comparison of the lower stratospheric age spectra derived from a general circulation model and two data assimilation systems, J. Geophys. Res., 108, 4113, doi:10.1029/2002JD002652, 2003.

Sherwood, S. C. and Dessler, A. E.: Convective Mixing near the Tropical Tropopause: Insights from Seasonal Variations, J. Atmos. Sci., 60, 2674-2685, doi:10.1175/15200469(2003)060;2674:CMNTTT ¿2.0.CO;2, 2003.

Sherwood, S. C., Chae, J.-H., Minnis, P., and McGill, M.: Underestimation of deep convective cloud tops by thermal imagery, Geophys. Res. Lett., 31, L11102, doi:10.1029/2004GL019699, 2004.

Stohl, A., Wernli, H., James, P., Bourqui, M., Forster, C., Liniger, M. A., Seibert, P., and Sprenger, M.: A New Perspective of Stratosphere-Troposphere Exchange, B. Am. Meteorol. Soc., 84, 1565-1573, doi:10.1175/BAMS-84-11-1565, 2003.
Stohl, A., Cooper, O. R., and James, P.: A Cautionary Note on the Use of Meteorological Analysis Fields for Quantifying Atmospheric Mixing, J. Atmos. Sci., 61, 1446-1453, doi:10.1175/1520-0469(2004)061<1446:ACNOTU>2.0.CO;2, 2004.

Stohl, A., Forster, C., Frank, A., Seibert, P., and Wotawa, G.: Technical note: The Lagrangian particle dispersion model FLEXPART version 6.2, Atmos. Chem. Phys., 5, 2461-2474, doi:10.5194/acp-5-2461-2005, 2005.

Wang, P. H., Minnis, P., McCormick, M. P., Kent, G. S., and Skeens, K. M.: A 6-year climatology of cloud occurence frequency from Stratospheric Aerosol and Gas Experiment II observations (1985- 1990), J. Geophys. Res., 101, 29407-29429, doi:10.1029/96JD02962, 1996.

Winker, D. M. and Trepte, C. R.: Laminar cirrus observed near the tropical tropopause by LITE, Geophys. Res. Lett., 25, 33513354, doi:10.1029/98GL01292, 1998.

WMO: Scientific Assessment of Ozone Depletion: 2006, Technical report no. 50, World Meteorological Organization, Geneva, 2007.

Wohltmann, I. and Rex, M.: Improvement of vertical and residual velocities in pressure or hybrid sigma-pressure coordinates in analysis data in the stratosphere, Atmos. Chem. Phys., 8, 265272, doi:10.5194/acp-8-265-2008, 2008.

Wright, J. S., Fu, R., Fueglistaler, S., Liu, Y. S., and Zhang, Y. The influence of summertime convection over South-East Asia on water vapor in the tropical stratosphere, J. Geophys. Res., doi:10.1029/2010JD015416, in press, 2011.

Yang, Q., Fu, Q., and Hu, Y.: Radiative impacts of clouds in the tropical tropopause layer, J. Geophys. Res., 115, D00H12, doi:10.1029/2009JD012393, 2010. 